\title{
Snowball Earth
}

\section{Indranil Banik*}

Scottish Universities Physics Alliance, University of St Andrews, North Haugh, St Andrews, Fife, KY16 9SS, UK

Keywords: Palaeolithic; Glaciation; Neoproterozoic; Chain reaction; Snowball Earth

\section{Historical Development}

Our ability to unlock the secrets of the ancient earth and understand events that occurred long before humans had evolved is a remarkable and unique accomplishment of modern science. On Earth, this is achieved mainly by looking at the record of these times that is preserved in ancient rocks. The events recorded within them would be almost incomprehensible without an understanding of the laws of physics that led to their occurrence.

250 years ago, the theory that the ice sheets, now confined to mostly within the Arctic and Antarctic Circles, had in the northern hemisphere extended very much further south and stayed there every summer for thousands of years; had yet to be accepted by the vast majority of scientists and certainly of the general public. Today, this theory of recurring Palaeolithic ice ages in the past 2.5 million years is widely accepted [1]. Its role in driving human evolution is also appreciated, the events having led to droughts in Africa with the resulting advantage to hunting rather than gathering (which ultimately led to a much larger brain size). Also important was the opening up of land bridges between continents due to a drop in sea level, allowing humans to reach them and thereby spread across the planet more easily.

Although this theory of Palaeolithic glaciations is now generally accepted, these events seem almost benign when compared to what seems to have happened when our earliest ancestors, single-celled life forms; inhabited the primordial oceans in the pre-Cambrian age of earth. For it now appears that, repeatedly in the Earth's long history, and for prolonged periods of geologic duration; the entire planet may have been covered in ice. This new theory, going by the name of 'Snowball Earth', has gained increasing support from mounting evidence in the last few decades. It may have also played a key role in shaping the evolution of primitive proto-cellular life into complex multi-cellular life forms, something that may be the key barrier to intelligent life developing on a planet. It took billions of years for this step to occur, whereas simple life emerged relatively rapidly after the formation of the Earth.

These glaciation events were so extreme that our entire planet would have been nearly as cold as the present Mars, and certainly colder than the Moon. In fact, it would have been cold enough to sustain the coldness, which is one key reason why it lasted so long. The mechanism responsible for this is called the ice-albedo feedback effect. Ice forms at low enough temperatures, and it reflects enough sunlight to reduce the temperature even further. Considering that almost every material is less reflective than ice (usually by a huge margin), the effect is considerable.

Under certain conditions, the ice will advance further and further until it reaches within $30^{\circ}$ of the Equator. At this point, if a small perturbation to the climate system increased the amount of ice cover by one arbitrary 'unit', the temperature would decrease sufficiently to allow the formation of one more unit of ice (due to the reflection of more sunlight). This would be a self-sustaining geological version of a 'chain reaction'. There could then be no stopping the ice from covering the entire planet, including the tropical oceans! As we will see later, however, small gaps in the ice cover sufficient to prevent a total extinction of surface life on Earth would likely have been left for a variety of reasons.

Although a global glaciation might have been disastrous for many living organisms then present, the extreme stress put upon them may have accelerated the pace of evolution considerably, leading ultimately to the Cambrian explosion. The unusual chemistry and surface processes (or lack of them) that occurred during these extreme glaciations may also have helped the development of complex multi-cellular life-forms and of land-dwelling animals that needed far more oxygen than would normally have been present in the atmosphere, having only just evolved primitive lungs. Some key chemical reactions could have required as much as $40 \%$ oxygen in the atmosphere.

Now recognised as one of the most important sites containing evidence for a Snowball Earth event during the aptly named Cryogenian Period of the Neoproterozoic eon, the Flinders Ranges in Australia were first explored in great depth by Douglas Mawson, an Australian Geologist born in England. He identified glacial deposits, which was only really possible as he had spent a lot of time in Antarctica! Nonetheless, before the development of the theory of plate tectonics, it was puzzling and suggested the possibility of a Snowball Earth event (Figure 1).

However, these discoveries occurred only a few years before Alfred Wegner proposed in 1912 the theory of continental drift, arguably one of the greatest advances ever made in geology. This immediately led to the much more plausible speculation that Australia had been much closer to the poles at the time the evidence of glaciation was deposited. This seemed reasonable as the glaciations were nearly a billion years ago.

The modern theory of a snowball Earth was first proposed in 1964 by Walter Brian Harland, a geologist at the University of Cambridge [2]. He found evidence of glacial tillites in Svalbard (Norway) and in Greenland, and evidence that they were near the Equator at the time the glacial deposits were laid down. In particular, he and D.E.T. Bidgood analysed the Moelv tillite in the Sparagmite District of central Norway in 1959. The deposits in Greenland were analysed in 1961 by the same two people.

Strong evidence for seafloor spreading and continental drift came soon afterwards. Much effort was therefore placed upon locating where the deposits in Greenland and Norway had actually been at the time of interest. The conclusion reached by Harland as a result of his palaeomagnetic studies was that the glacial deposits had been laid down

*Corresponding author: Indranil Banik, Scottish Universities Physics Alliance University of St Andrews, North Haugh, St Andrews, Fife, KY16 9SS, UK, Tel: 00447806375268; E-mail: ib45@st-andrews.ac.uk

Received July 02, 2016; Accepted August 17, 2016; Published August 25, 2016 Citation: Banik I (2016) Snowball Earth. Astrobiol Outreach 4: 153. doi: 10.4172/23322519.1000153

Copyright: (c) 2016 Banik I. This is an open-access article distributed under the terms of the Creative Commons Attribution License, which permits unrestricted use, distribution, and reproduction in any medium, provided the original author and source are credited. 


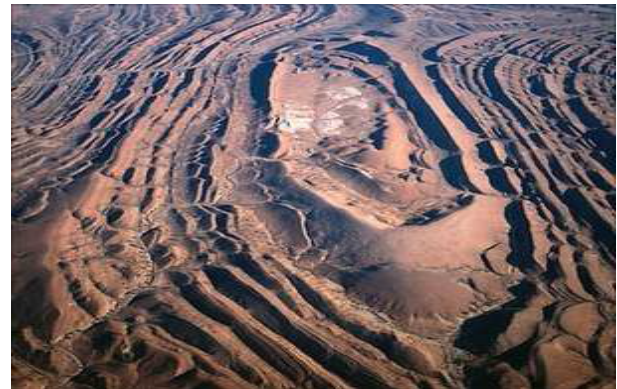

Figure 1: The Flinders Ranges in Australia.

near the Equator, within about $10^{\circ}$ [3]. He was forced to conclude that the temperature must have been low enough to allow such ice sheets to form, even this close to the Equator; and that therefore the entire Earth was covered in ice at the time. He also suggested a possible link to the Cambrian explosion, just after this glaciation.

In more modern times, more evidence of this nature has been found elsewhere, including in the Flinders Ranges in Australia, which were also very close to the Equator. The pattern is not coincidental, for the occurrence of almost all of the Earth's land masses near to the Equator was critical to the occurrence of a Snowball Earth. The uniqueness of the situation is thought to explain why it has not occurred since then.

Climate models developed by Mikhail Budyko of the Main Geophysical Observatory in Leningrad in 1969 showed the sensitivity of the Earth to an effect called the ice-albedo feedback effect [4]. This would allow glaciers to extend and reach the Equator, provided that the model was started with the maximum extent of ice cover close enough to the Equator. In fact, only half of the land area of the Earth needs to be ice-covered, corresponding to a latitude of $30^{\circ}$. This is very close to the Equator, but it seemed reasonably clear that the glacial deposits found in Australia were deposited at a latitude of closer to $10^{\circ}$. Despite the crudeness of the models used, it is clear that no realistic model of the climate of the Earth would allow ice this close to the Equator without a global glaciation (Figure 2) [5].

A physical understanding of the climate of the Earth during these ancient times was needed to fully explain what actually occurred in a Snowball Earth, in particular the conditions and mechanisms necessary to freeze the entire planet and also to thaw it. The last point was for a long time really troublesome, and, as we shall see, it explains why the Snowball state lasted for so long. After all, the state, extremely uncomfortable as it would undoubtedly be, is not unstable but rather extremely stable. This led to Mikhail Budyko claiming that, unstable as the Earth might be to the ice-albedo feedback effect, it could not actually have run out of control and led to the so-called 'ice catastrophe', for there was not yet any known mechanism for recovery. Also, it seemed certain that life would be completely exterminated by the hypothetical event, contradicting fossil records as well as being uncomfortable to imagine.

More evidence has followed since the 1970s, sometimes using the latest technologies but often just doing what Harland and others like him did at more sites around the world [6]. One notable site is in Namibia, explored by Hoffman and Daniel at Harvard [7]. It contains evidence of rapid climate change, from a glacial setting to a tropical setting. This is easily visible to the naked eye. An ordinary glaciation would look very different in the geologic record, and such sudden changes are very rare.

\section{How did it happen?}

\section{The greenhouse effect}

Although ice ages that extend the ice cover in the northern hemisphere to the middle of Europe are known to have occurred (by geologic standards) very recently, ice ages that went much further south and covered the entire planet are incredibly rare. No evidence has been found for such events in the last 600 million years. Conditions prior to this time must have been different in such a way as to allow a global glaciation to occur. To understand this, it is necessary to understand why the Earth is not always frozen and then to understand why these warming mechanisms should have failed.

It is well known that without an atmosphere, the temperature of the Earth, as well as varying enormously, would be on average $-18^{\circ} \mathrm{C}$. The Earth is about $35^{\circ} \mathrm{C}$ warmer because of the greenhouse effect. Gases like carbon dioxide and methane can absorb and re-radiate heat emitted by Earth. The absorption and subsequent re-radiation of infrared radiation within a tiny fraction of a second may not seem like much, but it has profound consequences. This is because, in equilibrium, the Earth must lose as much energy to space as it receives from the Sun.

This occurs at a certain temperature, and according to Planck's Law of Radiation, a higher temperature leads to a greater amount of energy loss (and vice versa). In fact, part of the reradiated energy is absorbed by greenhouse gases like carbon dioxide and half of this (roughly) comes back down to Earth instead of being lost to space. This means the Earth finds it harder to radiate energy away, so it needs to warm up even more to radiate as much power as it receives. The effect is like putting on a blanket.

Greenhouse gases can absorb infrared radiation as they have an asymmetric bond stretching mode, which is capable of inducing a change in the magnitude or direction of the dipole moment (or a change in the way the centres of positive and negative charge are separated, if at all). This is possible if a covalent bond joins atoms of different elements (so nitrogen and oxygen do not contribute to this effect). The idea is that an atom is better at holding onto electrons in a covalent bond compared with the other atom in the bond. This will cause it to have a higher electronegativity value on the Pauling Scale, which is just a way to calculate this effect numerically.

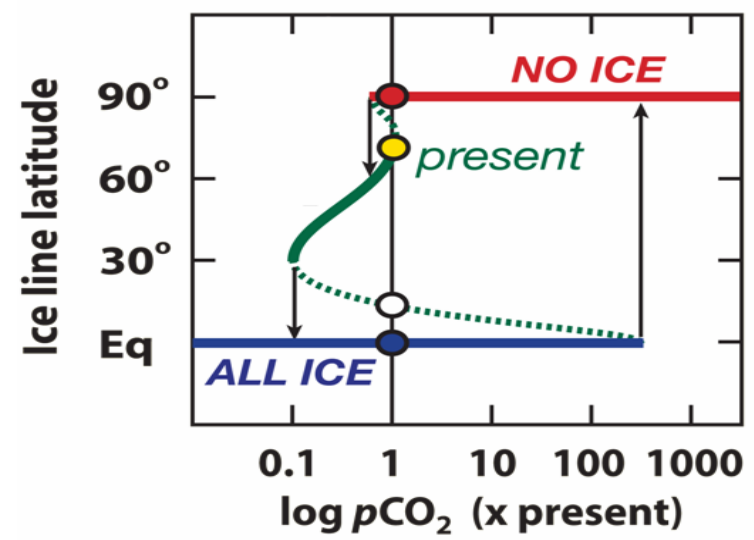

Figure 2: A Budyko-Sellers type climate model using energy-balance (equilibrium) methods. Dotted regions represent unstable solutions. Notice how a tenfold reduction in $\mathrm{CO}_{2}$ can cause global glaciation, requiring more than a hundred-fold increase to deglaciate it. As well as covering the entire Earth, the ice sheets can also vanish suddenly, possibly in this century. 
A good example is with carbon dioxide, the most important greenhouse gas. The electrons in a $\mathrm{C}=\mathrm{O}$ bond spend a little more time around the oxygen atom than the carbon atom. However, the molecule is symmetric, so the centres of positive and negative charge are at the same position (the centre of the molecule) (Figure 3). In this state, there is no dipole moment. If the molecule vibrates, with the carbon atom 'above' the oxygen atoms, the centre of negative charge will move 'below' the carbon atom. So will the centre of positive charge, but in a linear way (as protons are at the centre of mass of atoms), whereas the covalent bond is non-linear (the electrons behave in a more complicated fashion). This will introduce a separation of the centres of charge, a dipole; where there was none previously (Figure 4).

The nuclei contain all the protons, and as their position is the centre of mass of the atom (due to their weight being much higher than that of the electrons), moving the atom (or it's centre of mass) has a linear effect on the centre of positive charge. The centre of negative charge will depend on how the orbits of the electrons respond. This is highly nonlinear. Thus, the two displacements are unlikely to be the same.

The centres of charge can move in a periodic fashion if the molecule is vibrating. Infrared radiation carries electric and magnetic fields, and the electric field is able to act on this dipole and 'force' the vibration if it is at the same frequency. This leads to a resonance effect and the absorption of the infrared photon. The energy is eventually lost by collisions with other molecules or by radiation.

The greenhouse effect works because the spectrum of sunlight is very different to that of infrared radiation emitted by the Earth. The surface of the Sun is at a temperature of $6000^{\circ} \mathrm{K}$, so very little of its energy is at the fairly long wavelength of $4260 \mathrm{~nm}$, which is strongly absorbed by $\mathrm{CO}_{2}$. However, this is not true for the Earth, which is at a much lower temperature (the spectra are given by Planck's Law of Radiation). This means that sunlight can come through the atmosphere without any trouble, but the energy will find it much harder to escape if carbon dioxide is present (Figure 5).

Carbon dioxide is not the only greenhouse gas. Methane is also one, but its level is low as it gets oxidised to carbon dioxide in an average time of about a decade. Most of the greenhouse effect is due to a third greenhouse gas: Water vapour. It is part of a positive feedback loop, because warmer air is capable of holding more moisture. This feedback will roughly double the warming that man-made greenhouse gases, mainly carbon dioxide; would have caused 'on their own'. The effect on clouds, and the effect of clouds on the climate; is at present highly uncertain and so not discussed.

The reason why carbon dioxide is so important and why tiny changes in its levels are significant compared with changes in the concentration of the more important greenhouse gas water vapour is the long residence time of carbon dioxide in the atmosphere. Unlike water vapour, which comes and goes on timescales of a few days; extra carbon dioxide emitted into the atmosphere will be removed in about 100 years or more. The variations in water vapour concentration are too rapid to actually influence the long-term climate of a region. Instead, this is mainly controlled by carbon dioxide and methane, with water vapour amplifying any changes.

Also critical is the distinction between something which can control the climate without being affected by it (a so-called climate forcer) and something which is very dependent on the climate itself (a climate feedback). On timescales of a century or so, only a climate forcer can affect the climate, while a feedback can amplify or reduce its effect. Methane has a short atmospheric residence time, but it can be treated as a climate forcer because temperatures do not immediately and significantly affect how much methane the atmosphere can or does hold (at least not as quickly as with water).

With a given amount of carbon dioxide, a pulse of water vapour, for instance, would just be absorbed into more rainfall. One simplifying assumption of climate models is that air always holds a fixed fraction, say $80 \%$; of the maximum amount of water vapour that it could possibly hold (which is temperature-dependent). Thus, humidity cannot be added to the model. If it was, the temperature rise is too small to raise the capacity of air to hold water vapour even by as much as was assumed added to the atmosphere in the first place. Thus, the extra water leaves the atmosphere within days.

Carbon dioxide and methane are fundamentally different from water vapour in the context of the climate of the Earth for one very important reason-the air temperature is nowhere near their condensation temperatures. Thus, small changes in temperature may affect the carrying capacity (and thus concentration) of water

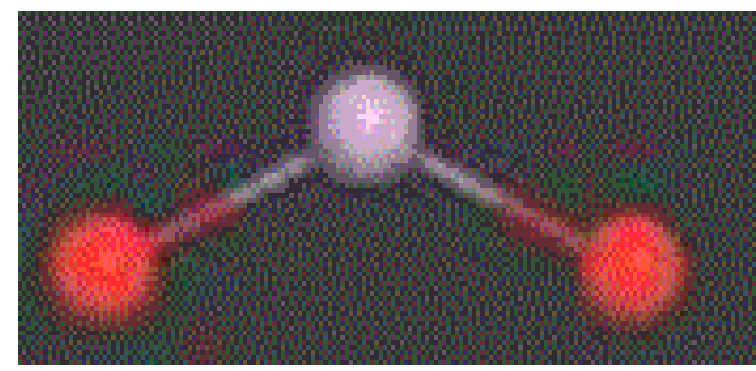

Figure 3: Carbon dioxide in a vibrational mode.

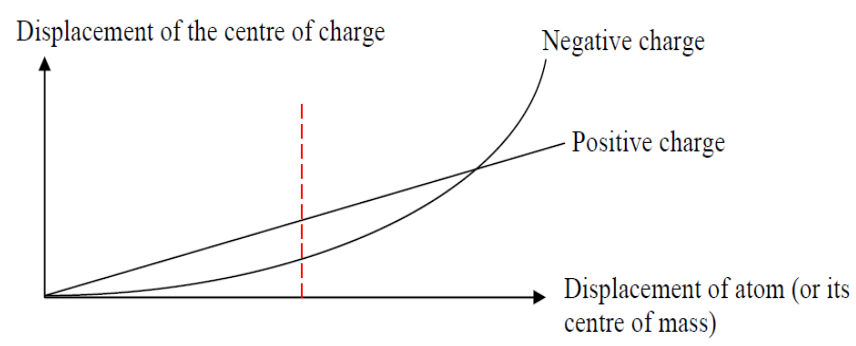

Figure 4: Rough idea of how the position of the atoms affects the positions of the centres of charge. A photon at the same frequency as the internal vibrations of the molecule (and so able to force them) always has the same energy ( $E=$ $\mathrm{hf}$ ), corresponding to (very nearly) the same amplitude of oscillations (red line).

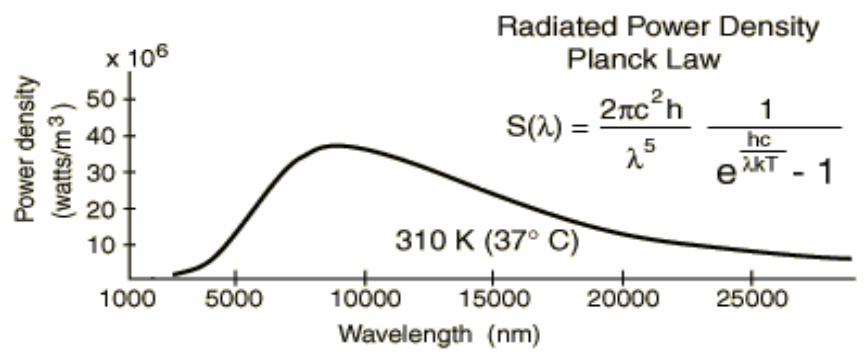

Figure 5: A black body radiation curve. The Sun emits practically no radiation at $4260 \mathrm{~nm}$ (the curve for the Sun peaks near only $500 \mathrm{~nm}$ as it is very hot). 
vapour but they cannot affect the concentration of the other major greenhouse gases. This is what allows them to force the climate-they are independently adjustable, or 'free parameters' (or very nearly so). Water vapour, as we have seen, cannot be considered in this way.

Adding a small amount of carbon dioxide to an atmosphere containing little of it is much more significant than adding some when a lot is already present. This is because less radiation in the wavelength bands absorbed by carbon dioxide has not already been absorbed by other $\mathrm{CO}_{2}$ molecules when fewer of them are present. The result is that a gas like methane, which is present at a very low level now; is a more potent greenhouse gas than carbon dioxide because adding one more molecule will warm the Earth more. If $\mathrm{CH}_{4}$ and $\mathrm{CO}_{2}$ concentrations were equal, adding more methane would have a smaller effect (as it absorbs more strongly in a narrow range of wavelengths).

\section{The carbonate-silicate cycle}

Carbon dioxide concentrations do vary. However, they do not usually go so low as to allow a global glaciation. This is because, on geologic timescales, there is a stabilising mechanism known as the carbonate-silicate cycle. Carbon dioxide enters this cycle from volcanoes and leaves due to the weathering of surface rocks. Rainwater carries with it small amounts of dissolved carbon dioxide. This can chemically weather rocks containing metals like calcium, with the result that calcium carbonate is formed (Equation 1).

$$
\mathrm{CaSiO}_{3}+\mathrm{CO}_{2} \rightleftarrows \mathrm{CaCO}_{3}+\mathrm{SiO}_{2}
$$

It is insoluble in water, so it gets deposited along with other debris when a river reaches the ocean, for instance. Living organisms can speed this up if they have carbonate shells, but it is not thought that they fundamentally alter the nature of the process. It should operate on any planet with active plate tectonics and liquid water.

The forward reaction (forming carbonates) is exothermic, so at low temperatures (compared to magma), it is favoured and the reaction mainly leads to the formation of calcium carbonate (limestone). According to Le Chatelier's Principle, a lower temperature will cause the reaction to oppose the change by generating heat, which is possible in the forward direction by producing more carbonate. At higher temperatures (e.g. when the limestone gets subducted into the interior of the Earth), the reverse reaction is favored since it absorbs some of the excess heat. This leads to carbon dioxide being produced, which is released by volcanoes (there is not sufficient time for the forward reaction to occur again, because the cooling happens suddenly).

The key thing is that this process acts as a negative feedback loop, so higher temperatures lead to a reduction in the concentration of carbon dioxide in the atmosphere, thereby limiting the temperature rise. This occurs because a higher temperature leads to increased rainfall and weathering. The result is more carbon dioxide is buried in the form of carbonates, so the temperature will eventually fall (the timescale for this is only a few thousand years, far less than geologic timescales).

The effect will also work for lower temperatures, which will reduce the rate of weathering and so allow carbon dioxide to accumulate in the atmosphere, assuming volcanoes are unaffected and (on average) always emit the same rate of carbon dioxide, at least on geologic timescales. In particular, ice cover will develop at low temperatures, shutting down weathering in polar regions and reducing the global rate of weathering. This effect keeps the Earth within the range of temperatures that allow liquid water on the surface, something for which we should be profoundly grateful.
However, it is clear that this process must have partially failed if the Earth was well below this range of temperatures and completely covered in ice. The Pre-Cambrian global glaciations were probably caused by the breakup of the supercontinent Rodinia, which was situated very close to the Equator. This is thought to have started $\approx 800$ million years ago. The geography would allow weathering rates to remain high while the temperature was falling, since the land mass was too close to the Equator to get covered in ice (for now). The ice cover could keep increasing, without weathering being significantly affected (rainfall is much less affected by temperature than is ice) (Figure 6).

The breakup of a supercontinent leads to a sharp increase in weathering rates, because areas that were far inland and got very little rain can now suddenly receive lots of rainfall from newly opened inland channels. This would lead to a sharp increase in weathering rates and consequent reductions in carbon dioxide concentrations in the atmosphere. This would probably have reduced global temperatures quite significantly. However, this would not lead to much change in the rate of weathering.

\section{The ice-albedo feedback effect}

The extent of ice cover could keep increasing, but it could not get too far because it would eventually hit the landmass and start shutting down weathering. However, before this points a positive feedback mechanism (or instability) in the Earth's climate comes into play. It is known as the ice-albedo feedback effect. Ice is far more reflective than ocean water, and so the advancing ice sheets would reflect more sunlight and reduce the temperature further. This kind of feedback is normally not that significant, because only a small area near the poles is usually ice-covered.

However, calculations by Mikhail Budyko of the Main Geophysical Observatory in Leningrad, and (based on his work) William Sellers at the University of Arizona in Tucson (USA), performed in the mid1960s; showed that if the ice cover extended to a latitude of about $30^{\circ}$, one extra degree of ice cover would lead to cooling sufficient to just cause one more degree of ice cover. The effect would be a chain reaction, eventually covering the entire Earth in ice within just a few thousand years [8].

The idea seemed completely implausible, because a mechanism for breaking out of such a state would not be proposed for at least 20 years,

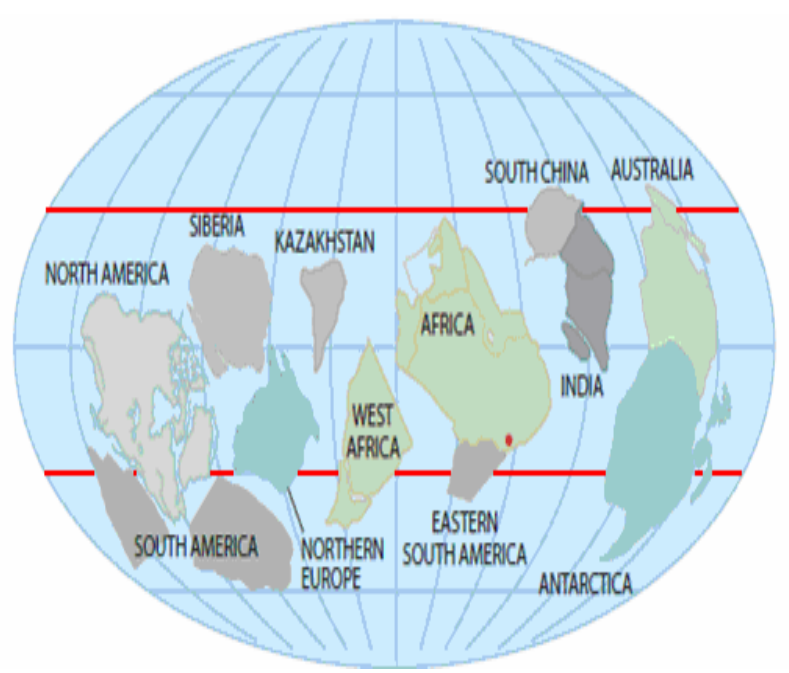

Figure 6: The (rough) positions of the Earth's continents 700 million years ago. The red lines are at $\pm 30^{\circ}$ latitude-unusually, almost all land is between them. 
and of course it relied on factors well outside the simple models used. The basic model Budyko used suggested that the planet would be in a stable equilibrium, with the temperature very low but unlikely to rise as so much sunlight was reflected and so little absorbed. Also, it was thought that, even if the state was not permanent, life would not be able to survive it. Photosynthesising organisms would face particular difficulty as they require liquid water and sunlight. A global glaciation seemed impossible to survive, as no open ocean would be left, and the ice sheets seemed certain to be kilometers thick.

Despite the objections, the basic idea is correct. At lower latitudes, one extra degree of ice cover has a bigger effect than at high latitudes, because the area contained within this degree is greater. Also, equal areas at lower latitudes receive more sunlight than at higher latitudes, because their inclination to the Sun is smaller. Thus, an increase in albedo (reflectivity) at lower latitudes will be more significant than one at higher latitudes. Combined, these effects explain why, once beyond the critical latitude, the feedback effect will only get stronger. There would now be no natural mechanism that could reasonably be expected to prevent the ice sheets from reaching the Equator.

The climate instability found by Budyko and Sellers is now recognised to be a real one, and there is much concern about the opposite extreme in which the ice cap at the Arctic and in Greenland disappears completely, causing a large rise in sea level. The instability would mean that the ice 'only' needed to come within $30^{\circ}$ of the Equator, and it is possible for almost all of Rodinia to have been closer than this to the Equator (this represents half of the Earth's surface area, not one third). Thus, once the ice cover extended that far, even a complete stop to weathering would not be sufficient to prevent a global glaciation (little carbon dioxide is outgassed by volcanoes in a few thousand years-the carbonate-silicate cycle is very slow). Once this occurred, the new state would for a long while be in equilibrium. The Earth would be far too reflective to have an equilibrium temperature even of $0^{\circ} \mathrm{C}$, and it was probably closer to $-40^{\circ} \mathrm{C}$ or even colder. There would seemingly be no escape from this state.

However, the glaciation was not permanent-after all, the Earth is not currently frozen! The mechanism required to allow an eventual thawing out from the snowball state was first proposed by Joseph Kirschvink of the California Institute of Technology in Pasadena, also the home of NASA's Jet Propulsion Laboratory [9]. His suggestion was an extreme version of the carbonate-silicate cycle normally in operation. With weathering completely halted by a global glaciation, there would be almost no carbon dioxide removal from the atmosphere.

However, it should still be possible for it to be released by volcanoesnumerous examples exist of volcanic eruptions under ice completely breaking through, most recently in Iceland with resulting disruption to air travel over Europe. Thus, it seems likely that carbon dioxide could still be released into the atmosphere, where it would remain (assuming that it did not freeze, for which the temperature needs to be above $-79^{\circ} \mathrm{C}$ ). This would lead to accumulation of it in the atmosphere.

Even with this mechanism, it would be very difficult to break out of such a glaciated state. The level of carbon dioxide would need to be approximately $29 \%, 800$ times higher than its present level. Even this would only just be sufficient to melt a narrow band of ice at the Equator. This would, however, lead to the ice-albedo feedback effect being run in reverse, with the open water now absorbing almost all of the incident solar radiation rather than reflecting it like ice [10].

The consequent rise in temperature would melt even more ice, and the very high levels of carbon dioxide would lead to a fairly rapid thawing of the world out of its previously frozen state. The timescale for this is thought to be only a few thousand years, much shorter than the many millions of years the glaciated state is thought to have persisted for. However, the actual timescale for deglaciation is not well known.

\section{Limits to atmospheric carbon dioxide levels}

The accumulation of carbon dioxide may not be guaranteed just by the temperature being above that at which it freezes (which it is thought was the case, as this temperature is very low). Very high levels of carbon dioxide in the atmosphere might lead to unusual ocean chemistry and the removal of some of this carbon dioxide, possibly limiting the maximum amount of it that could remain within the atmosphere (Figure 7).

This requires a certain amount of ocean-atmosphere interaction. However, there would have been some ice-free regions near volcanic islands and possibly near the Equator. With even $1000 \mathrm{~km}^{2}$ of ice-free surface, the oceans would interact quite strongly with the atmosphere. On geologic time scales, they might even be in equilibrium (with respect to $\mathrm{CO}_{2}$ ) despite the ice. This would mean that the $\mathrm{pH}$ of the oceans would drop and they would become quite acidic. However, the interactions would still be too slow for the oceans to be oxygenated, because iron would still be released into them from hydrothermal vents and a huge amount of oxygen is required to oxidise it. Meanwhile, only a relatively small amount of carbon dioxide is released by volcanoes each year, so even a small amount of Open Ocean would suffice.

Chemical reactions could then proceed with metal ions like $\mathrm{Ca}^{2+}$, which would have been in the oceans due to weathering of surface rocks prior to the global glaciations and also due to hydrothermal vents. These would have led to the formation of carbonates, and these are only weakly soluble in water so they would precipitate out. At some level of carbon dioxide, the removal of it in this way would equal the volcanic outgassing rate. Ocean chemistry was therefore significant unless the ice-free area was less than $10 \mathrm{~km}^{2}$. This is unlikely due to volcanic islands and other geologic hotspots leading to a much larger area of probable ice-free ocean (Figure 8).

The equilibrium concentration might thus act as an upper bound on the level of atmospheric carbon dioxide. If it could not be exceeded and if removal processes became stronger with more $\mathrm{CO}_{2}$ (which is almost certain), the concentration of carbon dioxide would rise asymptotically towards this value rather than linearly. This means that the concentration of carbon dioxide at the so-called 'deglaciation threshold' would have to be below this limiting value for us to be here today.
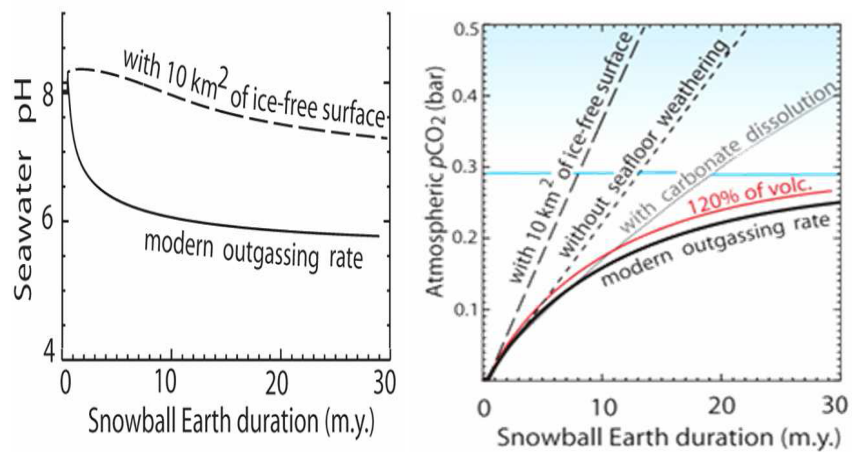

Figure 7: Model showing how ocean chemistry drastically changes with very high levels of atmospheric $\mathrm{CO}_{2}$, limiting the rise in its level in the atmosphere. This makes it quite difficult to reach the deglaciation threshold (blue line) and thereby end the Snowball Earth. The amount of volcanism may have been higher in the past-the effect of this is also shown (red curve). 


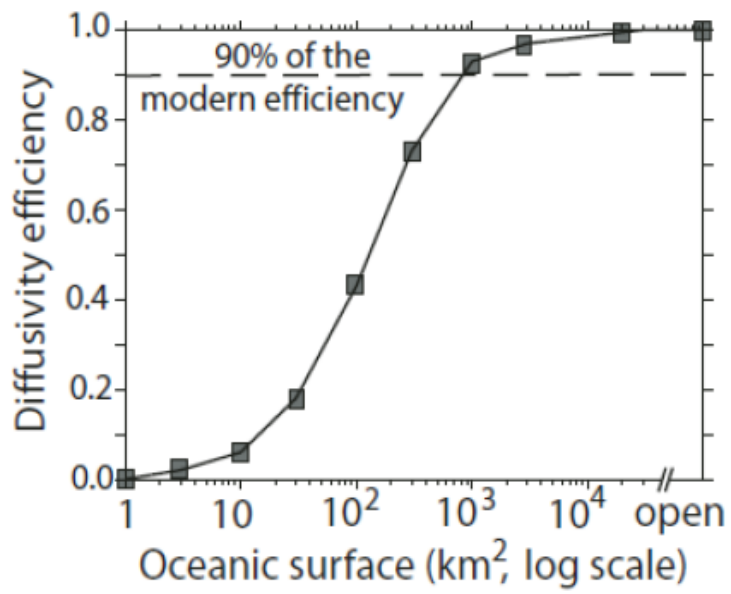

Figure 8: Model of how efficient ocean chemistry capable of removing carbon dioxide from the atmosphere would be under variable amounts of open water. Of all the millions of square kilometres of ocean, just 1000 remaining ice-free would mean reactions nearly as efficient as today! A lower efficiency still leads to significant $\mathrm{CO}_{2}$ removal (it builds up slowly), unless the efficiency is below about $10 \%$. The tiny amount of open ocean that this entails is considered unlikely.

Climate models have great difficulty in showing this to be the case. Although neither quantity is known very well, it seems that a $\mathrm{CO}_{2}$ concentration of $29 \%$ would probably be sufficient to initiate deglaciation. This is higher than the $13 \%$ initially thought as the Sun radiated $6 \%$ less power than it does now and other effects have been considered better. However, ocean-atmosphere models indicate great difficulty in reaching this much atmospheric $\mathrm{CO}_{2}$. Therefore, several possibilities need to be considered that could reduce the deglaciation threshold to a more attainable value.

\section{Other triggers for deglaciation}

One possibility is that volcanoes also put out something else with a great impact on the climate system-volcanic dust. This would greatly darken the ice at even tiny concentrations, and it is possible that the sharp variations in temperature that drive winds were greatly subdued in a Snowball Earth event. With only weak winds near the Equator, the dust may have managed to stay put and help the ice to absorb radiation from the Sun much better. Over millions of years, a great deal of dust would be put out, and it might go within the ice due to cyclical sublimation and snowfall.

However, it probably could not get too far below the surface. A lot of dust near the surface would make it much easier to break out of a glaciated state by reducing the albedo, or reflectivity, of the ice. The effect would have been similar to putting more carbon dioxide into the atmosphere, but dust would not be as easily removed. It might lower the deglaciation threshold sufficiently to allow this to occur with far less $\mathrm{CO}_{2}$ than the maximum level of it in the atmosphere. Contributions from meteoritic dust also need to be considered. It would probably not behave fundamentally differently to volcanic dust, but it would raise the total amount of dust even further.

Another possibility is that methane generated from anaerobic decomposition of organic matter (and possibly thermal decomposition) could have been stored and released suddenly, terminating a global glaciation as methane is a very potent greenhouse gas. The methane can be stored as methane clathrates, which look like ice and are stable at low enough temperatures and under sufficiently great pressures.
These could potentially form near the Equator during a global glaciation, because it is thought that this requires gas from a great depth (probably from fault lines) coming into contact with very cold sea water and eventually being locked up as ice. The water molecules crystallise into a cage-like structure capable of trapping other molecules like methane or $\mathrm{CO}_{2}$ within it. If the temperature were raised (e.g. by $\mathrm{CO}_{2}$ ), but not necessarily enough to initiate deglaciation; an entire deposit of clathrates could be destabilised (for a fixed depth, they are only stable below a certain temperature).

The oceans near the Equator would have been sufficiently cold and geologically active in some areas, and the global glaciations would have lasted long enough to allow clathrates to form. These clathrates could then destabilise at a high enough temperature in a runaway effect that leads to even higher temperatures and more clathrates being decomposed. The effect could be quite sudden and lead to the formation of a large region of ice-free ocean near the Equator before the methane gets oxidised. At that point, the albedo of the planet might have been reduced sufficiently to allow the ice-albedo feedback effect, combined with high levels of $\mathrm{CO}_{2}$ (but lower than previously thought), to deglaciate the entire planet quite rapidly.

One final effect that should be considered is the effect on the atmospheric pressure of vast amounts of carbon dioxide. A higher atmospheric pressure may have made the escape of heat to space more difficult, acting as an extra greenhouse effect. Higher pressures have rarely been included in climate models. With a $20 \% \mathrm{CO}_{2}$ concentration by volume, the effect may have been considerable. We do not usually think of 1 bar as being anything other than the mean atmospheric pressure at sea level on Earth, but this may not have been true during a global glaciation. The pressure is unlikely to have been drastically different to this, but even small differences can matter.

The unique conditions necessary to initiate a snowball Earth event suggest that it should be quite rare, but if the Earth's major landmasses were all located close to the Equator, then it seems that there could have been more than one global glaciation before the landmasses had moved significantly away from their positions. Indeed, evidence now suggests that up to four glaciations may have occurred during the Neoproterozoic Era (primarily during the very aptly named Cryogenian Period). The primary ones were the Sturtian Glaciation, 710 million years ago $(\mathrm{Ma})$ and the Marinoan Glaciation ( $635 \mathrm{Ma})$. The Gaskiers glaciation remains controversial [11].

\section{The Makganyene snowball Earth}

It is also possible that a similar event occurred during the Paleoproterozoic Era, about 2.4 billion years ago. At that time, the mechanism would have been very different. It seems that the much fainter Sun was being counteracted by a strong methane greenhouse effect. Methane was mainly produced by ocean-dwelling organisms (methanogens), and it is a much more potent greenhouse gas than carbon dioxide. It would not have been oxidised to carbon dioxide rapidly (as is the case today) because oxygenic photosynthesis had not yet become widespread. This would have allowed a much higher methane concentration in the atmosphere, counteracting the fainter Sun [12].

The development of oxygenic photosynthesis may have started long before this event, but it seems that a few glaciations (especially the Huronian) increased erosion rates and put trace elements like phosphorus into the oceans (it is so light that it is found mainly on continents-it floated on top of other heavier elements when the Earth was molten). This seems to be the limiting factor to oxygenic photosynthesis in the oceans, at least when there is sufficient iron (which 
there would be before widespread oxygenic photosynthesis to oxidise it and thus precipitate it out). A pulse of oxygen could thus have been produced, making previously rare oxygen-producing organisms much more common. As levels of phosphorus decreased again, organisms would have to try and become more efficient at using it.

The higher nutrient levels would have increased oxygen production, and higher efficiencies of using these nutrients were surely being achieved with time as well. The combined effects would probably have taken a long time to cause more oxygen to be produced than could be removed by oxidation of surface rocks, oceanic iron etc. The flux of iron from hydrothermal vents may have been decreasing (as the Earth became cooler and less geologically active), ultimately allowing the P: Fe ratio to rise high enough that more oxygen was being produced than needed to oxidise hydrothermal iron. Eventually, all the sinks of oxygen would be used up, and it would start accumulating in the atmosphere for the first time. The levels would initially be very low, close to one hundred thousandth of the present atmospheric level of oxygen.

Oxygen today can oxidise methane molecules to carbon dioxide, a greenhouse gas much less potent than methane at trapping heat; in an average time of about 10 years. With much lower oxygen levels, the methane would have lasted for a few million years before going into the lower energy oxidised state of carbon dioxide (and water vapour). With the 'methane greenhouse' destroyed, the planet would experience a sharp drop in temperature and global glaciation. Carbon dioxide would eventually build up to the enormous levels necessary to break the Earth out of this state.

A fainter Sun is thought to have made it much harder to break out of this glaciated state compared with the Neoproterozoic period, although volcanic outgassing may have been more vigorous as the interior of the Earth was warmer then. Also, ocean chemistry, which can remove carbon dioxide from the atmosphere; may have worked differently billions of years ago. It appears that this event, the Makganyene Glaciation, lasted from 2.32 to 2.22 billion years before today, much longer than the (still controversial) estimates for the duration of the Marinoan, not thought to have lasted much longer than 25 million years and probably half that.

\section{Evidence}

\section{Glacial deposits}

Much fieldwork has enabled the remarkable conclusion to be drawn that the entire Earth was once covered in ice. The first thing to prove is of course that there was ice at all. For this, geologists have a number of techniques. Fortunately, glaciers will leave certain traces behind that they once existed. In particular, they leave highly uneven pieces of rock, called glacial till, at their sides (lateral moraine) and at their end (terminal moraine). These are said to be poorly sorted, because they are unlike rivers which carry smaller and lighter particles further (e.g. into the sea) before depositing it, leading to particles of a similar size being found at a particular location.

Glaciers behave quite differently-they can carry particles of any size and where they end up depends on things like the topography or how far the glacier extended. However, because of their huge power, this is almost entirely independent of the particle itself. Even gigantic boulders can be carried by a glacier, and actually just as easily as tiny dust particles encased in ice-it all depends on where the glacial advance stopped or, for material under a glacier, if there was a 'lip' of land that could prevent it being dragged any further (though particles smaller than the size of the lip are more likely to get stopped at it than boulders much larger than it in size). They also carry rocks huge distances, and these may appear both large and out of place. Such rocks are called glacial erratics, and are quite easy (Figure 9).

Glacial till and erratics (or erratic rocks) of this nature have been identified in several locations. This includes the Svalbard and Greenland deposits mentioned and also several ones in Australia and Namibia (found more recently). These are usually dated to the period of interest using radioisotope dating. This involves the decay of Uranium-235 and 238 into different lead isotopes. Certain crystals could not incorporate lead into their structure, so any lead must be a radioactive decay product. Zircons are commonly used for this as they are very stable. The age will affect certain aspects of the hypothesis, such as the relation to other deposits formed elsewhere at the same time. The link to evolution of course depends strongly upon dating.

Deposits which appear glacial in origin could conceivably have been formed in warmer climates. The action of gravity on steep and unstable slopes could cause something similar to a landslide. This would lead to very little sorting of material by particle size, like in a true glacial deposit. The material deposited could easily include very large rocks. These would probably be quite localised, however.

Sedimentary rocks are usually thought of as having calmly settled down to the bottom of a body of liquid water and formed relatively flat layers. This is often true, but sometimes there could be strong eddy currents, really churning up the material. The currents would have sufficient energy to carry fairly large particles around almost as easily as smaller ones, leading to poor sorting. Really large boulders could not be moved around in this way. Also, most sedimentary rocks are relatively undisturbed, because they are deposited at a reasonable depth and currents are usually very weak there (deep waters are unaffected by surface processes like storms). Thus, most glacial deposits found from a certain period being in reality turbidites is quite unlikely.

The alternatives to a glacial origin mentioned above will only work fairly close to land, or at best on continental shelves (which can be quite steep). Large dropstones are difficult to carry into the deep ocean. This could be achieved by icebergs, however. They could break off ice sheets like they do today and carry material on them quite far. This is because they take a long time to melt, ice having a considerable latent heat of

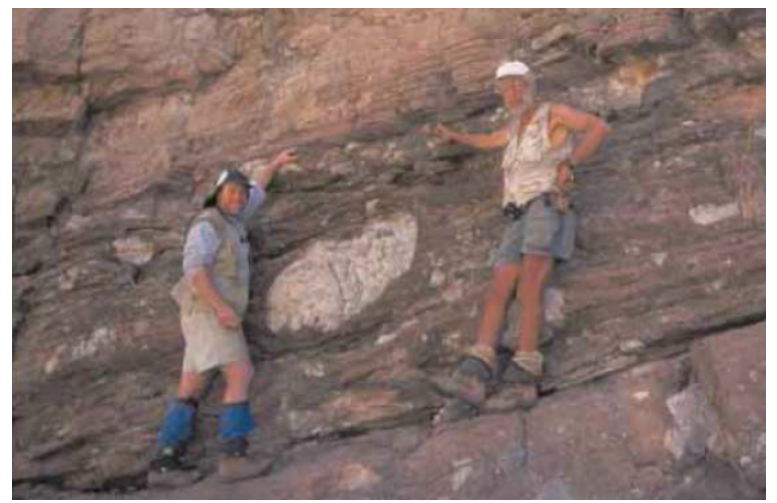

Figure 9: A glacial erratic found by Daniel P. Schrag and Paul F. Hoffmann in Namibia, probably from the Sturtian glaciation. The dark rocks below were glacial (notice how uneven they are). The lighter rocks, which suddenly take over above the heads of the geologists, are carbonates-usually associated with much warmer conditions (microbes help with carbonate deposition, and they like warm conditions). The transition is very sudden-a clue to dramatic climate change at the end of a global glaciation. Magnetic data also suggest a neartropical location. 
fusion (or melting) and the icebergs being enormous. Again, icebergs would only deposit large rocks at a small number of locations, and they cannot be expected to carry rocks above a certain size very often. On the other hand, a 'sea glacier' (an ice sheet over the ocean) with some ice flows (e.g. due to a slope) could easily achieve this if it extended up to the point of deposition while carrying rocks on top of it and later melted. This better explains how large rocks got into very flat layers of sedimentary rock, which require relatively undisturbed (and thus deep) waters.

The relative uniformity and great extent of the proposed glacial deposits suggests that most of them actually are glacial in origin. The alternative explanations also have trouble with very large rocks believed to be glacial dropstones. They can account for them, but require landslides that might have left other evidence behind, including much more disruption and localisation. The ease with which such dropstones have been found in Neoproterozoic rocks suggests that their abundance is similar to much more recent and confirmed glacial deposits, and not that these large rocks were rarely deposited. Some of the largest rocks would be difficult even for an iceberg to carry. Thus, the glacial origin of at least some (and probably most) of the deposits is almost certain.

\section{Paleolatitude determination}

Once glacial rocks have been found, it is necessary to demonstrate that the rocks were deposited near the Equator of the Earth. Combined with climate studies, this would be able to show that the entire planet was frozen over. The closer to the Equator the deposits were laid down, the more certain we can be that the entire Earth was glaciated.

Determining the latitude of a rock 600 million years ago is, however, not an easy task. It is done mainly by using the Earth's magnetic field and the assumption that it's magnetic axis and polar (rotation) axis were roughly coincident, at least when averaged over a few million years. Thus, a rock deposited today near the poles (where the magnetic field lines point down into the Earth) would have field lines pointing almost vertically. Nearer the Equator, the field lines would be almost horizontal.

The direction of the horizontal in ancient times can usually be determined because sediments are deposited in roughly horizontal layers. Although they may have folded later on, this layering is still visible in many cases. This information must then be used in careful magnetic analyses to find the latitude at the time the rock was deposited.

Early analyses by Harland and later analyses by Kirschvink and others have all found glacial deposits dated to the Cryogenian which must have formed near the Equator, near enough that there was a probable snowball Earth event [11]. The deposits in Australia were found to be within just $10^{\circ}$. These deposits and the magnetic field lines contained within them are the primary evidence that an extreme glaciation occurred approximately 650 million years ago. Therefore, the reliability with which paleolatitudes (Figure 10) [13] can be determined has come under intense scrutiny. The main problem that could occur is called secondary magnetization (Figure 11). As its name suggests, the rocks may have been magnetised at a much later date, when their orientation may have been different. Their latitude may have been different as well, complicating things further.

In the above diagram, it is easy to notice that case A would give readings that all clustered on $10^{\circ}$, whereas case $\mathrm{B}$ would give a much wider range. The fold test, originally proposed by John Graham at the Carnegie Institution, Washington in 1949; would take advantage of this fact. Real data involve some scatter, and he devised an accurate measure of this and if it was appreciably reduced by changing our view

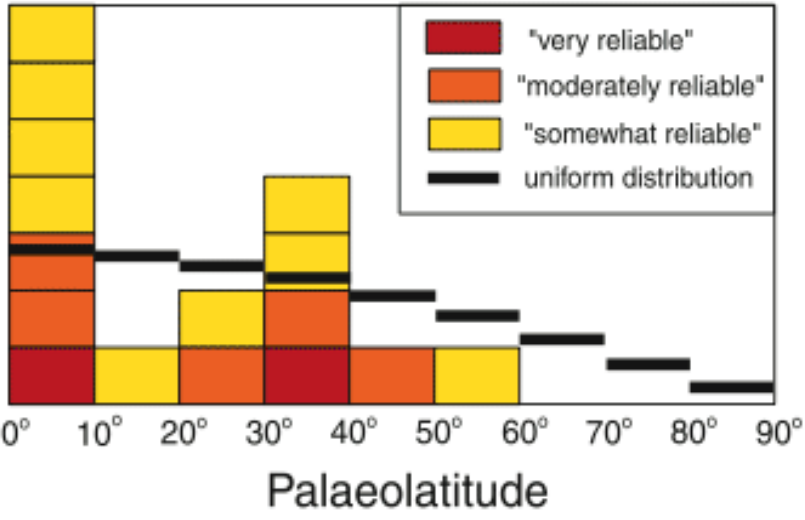

Figure 10: Paleolatitude distribution of glacial deposits from the Neoproterozoic. The reliability is that of the paleolatitude determination, not of the glacial nature of the deposits. The only very reliable data point shown whose existence requires a global glaciation is from the Elatina formation in the Flinders Ranges in Australia (the other one is a little too far from the Equator). Notice how the distribution of deposits is heavily biased towards low paleolatitudes.
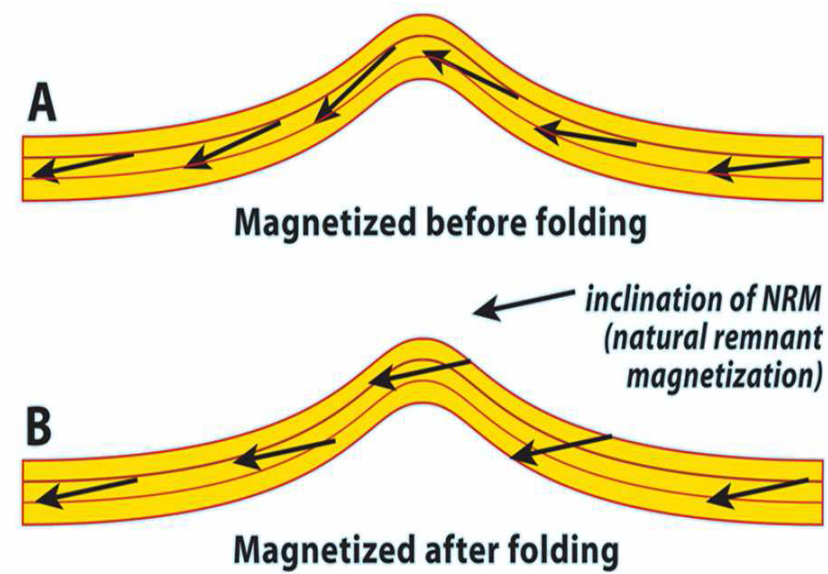

Figure 11: The problem of secondary magnetisation. In case A, sedimentary rocks are magnetised upon formation at a paleolatitude of $10^{\circ}$. The sedimentary layer subsequently folds due to tectonic activity. In Case $B$, the folding process causes the magnetic field to be 'reset', so the rocks are magnetised once more after the folding event. Assuming the geologist does not know this, and that the red lines are used as the horizontal direction; readings as high as $30^{\circ}$ could be obtained.

of what the horizontal was for each rock. For instance, we could assume it was the present horizontal or the red lines. In case A, the red line assumption would give a much lower scatter whereas in case B it would not (it would increase the scatter).

The magnetisation itself arises from the fact that, in a calm depositional environment (e.g. in deep waters); magnetic minerals in the sediments will cause them to be aligned in the direction of the Earth's magnetic field. The effect is very similar to what happens with a bar magnet and iron filings-they trace out the magnetic field lines. In choppy waters, this will not happen. There will be too much scatter in that case, and it cannot be reduced much (if at all) by assuming that folding occurred.

Thus, the fold test will reveal whether the magnetisation occurred prior to the folding event or after it, in which case it is secondary. Another check is to see if concurrent magnetic reversals are preserved in rocks that are assumed to date to the same period but are in 
different places. The Earth's magnetic field reverses direction at least once in every few million years, so the pattern of reversals should be the same at widely separated locations (recording the same period) if the magnetisation is primary. Gaps in the geologic record will appear during a global glaciation, but this technique can be powerful in the aftermath of such an event (or in more ordinary times).

\section{Isotope geochemistry}

13C: Modern times bring with them modern technologies, and one of them in particular has come to be recognised as a key player in the study of ancient environments-isotope geochemistry. The idea is that the ratio of the numbers of atoms of two different isotopes (atoms with the same number of protons but different numbers of neutrons) of the same element, or the concentration of one of these isotopes in absolute terms; is measurably affected by prevailing environmental conditions at the time the sample was laid down in the geologic record. There are many different isotope ratios that all contain very useful information, although careful interpretation of them is required.

One particular isotope of carbon that is of relevance is carbon-13, comprising about $1.1 \%$ of all naturally occurring carbon atoms (almost all the rest being carbon-12). These two isotopes are the only stable isotopes of carbon, and radioactive isotopes like carbon-14 will have almost completely decayed within just a few million years.

Carbon-13 is chemically identical to carbon- 12 because it has the same number of protons and so the same electronic structure. However, it is heavier and has slightly different physical properties. In particular, plants preferentially incorporate carbon-12 into their structures because it is slightly easier to move carbon atoms around if they are lighter. The result is that carbon-12 tends to get locked out of the carbon cycle if the plants get buried (e.g. sink to the sea floor). The carbon will again be released in millions of years when plate tectonics causes it to be brought down into the Earth and vaporised. The carbon eventually comes out through volcanoes. This will of course take many millions of years, far longer than biological timescales (Figure 12).

The key idea is that when there is a sudden drop in biological productivity, carbon-12 is no longer preferentially removed from the carbon cycle. Thus, the proportion of carbon atoms that are carbon-12 in the geologic record will rise, causing the proportion of carbon-13 atoms to fall. This is called $\delta^{13} \mathrm{C}$, and of course it will change under these circumstances. Its value can be used to infer the level of biological productivity (assuming the inorganic carbon flux did not significantly change).

This type of extreme drop in $\delta^{13} \mathrm{C}$ in practically the same geologic layers as those associated with glaciation near the tropics is quite suggestive of a drop in biological productivity triggered by the onset of global glaciations, which led to lower temperatures and less open water. Carbonates are not deposited during the glaciations.

The end of a period of global glaciation would have been a spectacular event, brought about by enormously high concentrations of carbon dioxide in the atmosphere (from volcanoes). This would have accelerated the deposition of carbonates, which are formed from the reaction of carbonate ions with metals. Carbonate ions are derived primarily from carbonic acid in rain reacting with metals. The high temperatures after a global deglaciation would lead to huge amounts of evaporation and rainfall, causing weathering (especially of some of the glacial deposits, which would have been ground up and had their surface area increased). Such a high rate of weathering would cause the deposition of vast quantities of carbonates, exactly as observed (Figure 13).

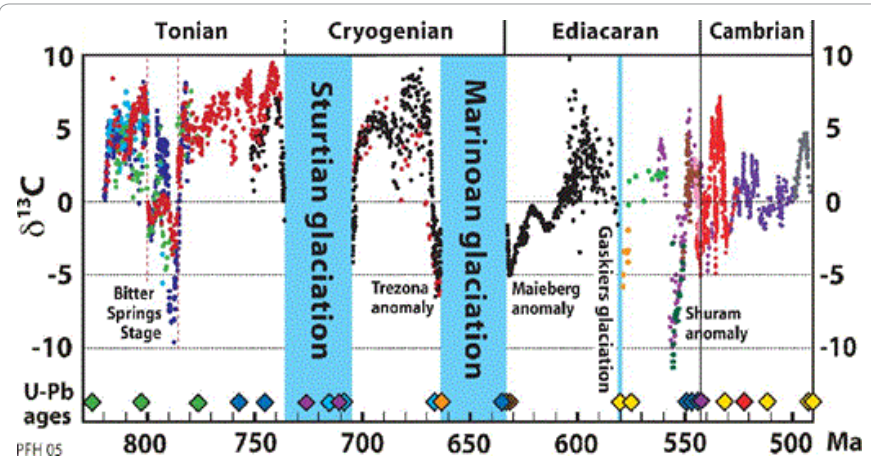

Figure 12: The Sturtian and Marinoan Glaciations, thought to be global in extent, shown up clearly in this graph of carbon-13 (thought to be an indicator of biological productivity). The glaciations are at 710 and $650 \mathrm{Ma}$. Evidence for a later glaciation at $580 \mathrm{Ma}$ also shows up, although its nature remains controversial. The mantle value for $\delta^{13} \mathrm{C}$ is believed to be -5 to $-6 \mathrm{ppm}$. When this actually was the sediment value, photosynthesis had nearly ceased.

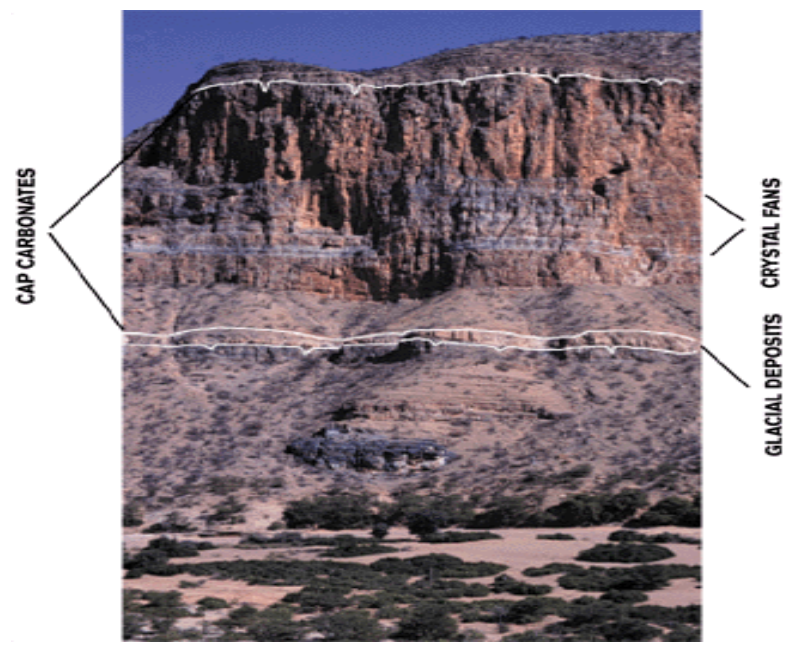

Figure 13: A rock outcrop in Namibia showing cap carbonates deposited after a period of glaciation. The crystal fans must have formed from waters supersaturated with calcium carbonate, suggesting high atmospheric $\mathrm{CO}_{2}$ levels.

The carbonates would thus be primarily abiotic in origin, unlike most carbonates deposited today. This would mean the carbon isotope ratio in these carbonates would not be different from the ratio in the mantle (biological carbonates contain much less carbon-13). In fact, this is also observed, the ratio being entirely consistent with this scenario and inconsistent with a primarily biological origin (e.g. due to shells of organisms), although organisms were still involved to a small extent. Extreme conditions would be required to break out of a Snowball Glaciations Earth, and evidence of such conditions has been found.

Other evidence concerns the timing and duration of the proposed global glaciations. These would have been some of the longest glaciations ever (much longer than more recent ones). Indeed, evidence has been found suggesting an extremely long duration to these events, consistent with the very long timescales required by climate models. Such evidence comes in the form of the (still poorly understood) magnetic reversals. These occur when the North and South magnetic poles of the Earth switch sides, so a compass needle that used to point north now points south (and vice versa).

This may sound like a rare and strange event, but it is thought to occur at least once in every few million years, with at least 100,000 or 
so years required for each event. The rock strata containing suggested glacial deposits contain within them minerals that would be aligned in the direction of the Earth's magnetic field lines at that point. Once deposited, this arrangement would be locked, and could be read with a good magnetometer. In fact, the arrangement reverses quite a few times during this period, suggesting that the glaciations were much longer than more recent ones.

Iridium: Still other evidence that may more accurately determine the duration of the Snowball Earth events is the concentration of iridium. This element was made famous when a very large anomaly in its concentration 65 million years ago alerted scientists Walter and Luis Alvarez to the possibility of a large meteorite impact at the time, now widely accepted to have caused the extinction of the dinosaurs and allowed our existence. Their conclusions were based upon the fact that iridium is very rare in Earth's crust, having sunk to the core when the Earth was molten. Most iridium on the surface comes from cosmic dust, derived from the debris of asteroid collisions.

A similar anomaly has been found at the end of some of the proposed global glaciations, and just before the deposition of the cap carbonates from weathering. It is thought that large amounts of iridium dust would have accumulated on top of the ice sheets, and when they melted, it would have been deposited in the oceans at a much higher rate than usual. This would occur immediately after the deglaciation, with the weathering taking slightly longer to show up in the geologic record of these times.

The total amount of iridium, while still small compared to other elements, nonetheless indicates a duration of about 12 million years for the Marinoan glaciation. The average iridium flux delivered to the Earth's surface over this period could be different from the modern value (e.g. it is not always the same, rare events like a large impact etc.). However, the amount is quite high, requiring a lot of volcanism or a large impact. Moreover, this happened after both the Marinoan and the Sturtian glaciations, making this even less likely. Element ratios are also very characteristic of asteroids.

10B and 11B: Isotopic evidence also exists for some of the extreme environmental conditions likely during a global glaciation. The very high levels of atmospheric carbon dioxide and consequent acidification of the oceans (which is a problem in our time too) would lead to a change in the state of boron in sea water. Boron is a light element (so one extra neutron in an isotope significantly affects the atomic mass of that isotope).

Boron is rare in seawater and exists mainly in co-ordination with hydroxide ions. The two forms, triangular and tetrahedral; exist in equilibrium (Equation 2).

$$
\mathrm{B}(\mathrm{OH})_{3}+\mathrm{H}_{2} \mathrm{O} \rightleftarrows \mathrm{B}(\mathrm{OH})_{4}^{-}+\mathrm{H}^{+}
$$

A higher $\mathrm{H}^{+}$concentration (or a lower $\mathrm{pH}$ ) will shift the equilibrium to the left (using up some of the excess $\mathrm{H}^{+}$ions-Le Chatelier's Principle). This will increase the fraction of boron in the $\mathrm{B}(\mathrm{OH})_{3}$ (triangular) state (Figure 14).

Naturally occurring boron consists almost entirely of two stable isotopes, boron-10 (percentage abundance $~ 20 \%$ ) and boron-11 (the remaining $80 \%$ or so). What is really surprising is that the fraction of tetrahedral species containing a central boron-10 is slightly more than its percentage abundance. The following reversible reaction, which is not changing anything at all (chemically), has an equilibrium constant just above 1 (Equation 3).

$$
{ }^{10} \mathrm{~B}(\mathrm{OH})_{3}+{ }^{11} \mathrm{~B}(\mathrm{OH})_{4}^{-} \rightleftarrows^{11} \mathrm{~B}(\mathrm{OH})_{3}+{ }^{10} \mathrm{~B}(\mathrm{OH})_{4}
$$
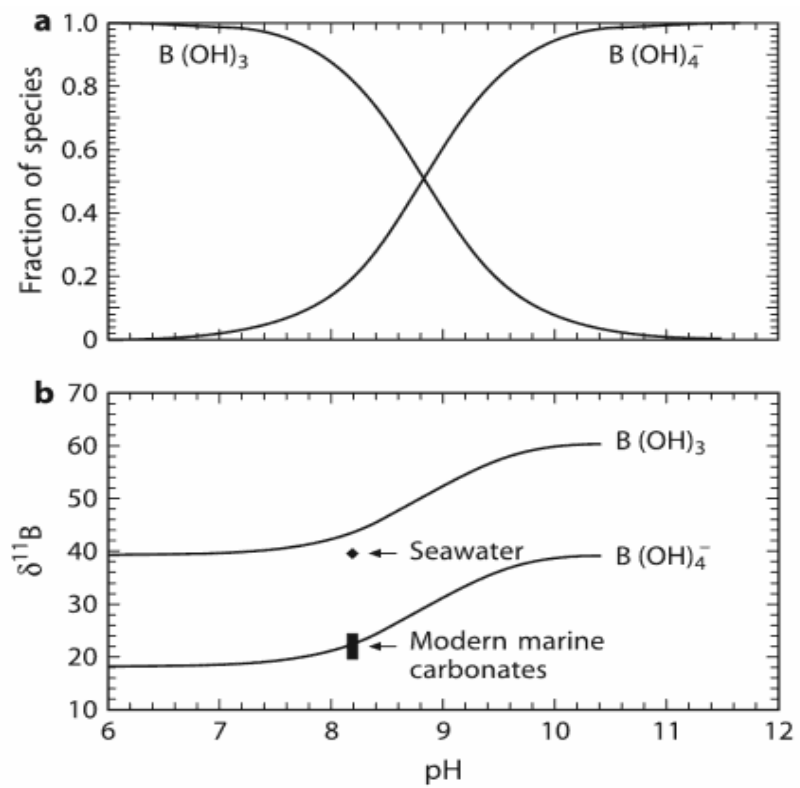

Figure 14: The relative abundances of $\mathrm{B}(\mathrm{OH})_{3}$ and $\mathrm{B}(\mathrm{OH})_{4}^{-}$in water and their isotopic composition as a function of water $\mathrm{pH}$. The temperature has a small effect. $\delta^{11} \mathrm{~B}$ for seawater today is $+39.5 \mathrm{ppm}$ relative to an agreed standard.

This is because of molecular vibrations. The $10 \mathrm{~B}(\mathrm{OH})_{3}$ and $11 \mathrm{~B}(\mathrm{OH})_{3}$ are chemically identical, so their sizes are determined by electrostatic forces (which are unchanged by an extra neutron). However, the lighter isotope of boron will be able to vibrate at a higher frequency. The best way to understand this is to imagine a simple spring, but the spring constant is determined solely by electrostatic forces. An equal spring constant and lower mass leads to a higher frequency of vibration.

The higher frequency means that photons capable of exciting a particular vibrational mode will also need to be at a higher frequency. Such photons have more energy. Therefore, $10 \mathrm{~B}(\mathrm{OH})_{3}$ will absorb more energy from an infrared photon than $11 \mathrm{~B}(\mathrm{OH})_{3}$ for the same vibrational mode. This leads to a higher amplitude of vibrations.

Vibrations have an effect on reaction kinetics. This is because the $\mathrm{B}(\mathrm{OH})_{3}$ contains three negatively charged $\mathrm{OH}$ - ions and these tend to repel other $\mathrm{OH}^{-}$ions that may be attempting to bond with the boron. However, vibrations will help because the central boron nucleus can momentarily rise above the plane defined by the three $\mathrm{OH}$ - ligands. Then, the $\mathrm{OH}^{-}$attempting to bond with the boron does not need to come as close to the other $\mathrm{OH}$ - ions already joined on to the boron.

This will make the reaction more likely to proceed, and therefore the $\mathrm{B}(\mathrm{OH})_{3}$ can more easily be converted into $\mathrm{B}(\mathrm{OH})^{4-}$ if the central boron is $10 \mathrm{~B}$ than if it is $11 \mathrm{~B}$. This results in $\mathrm{B}(\mathrm{OH})^{4-}$ being enriched in boron-10 relative to what we might expect. The effect is itself $\mathrm{pH}$ and temperature dependent, but the temperature dependence is small so only the $\mathrm{pH}$ dependence is shown. A value for $\delta^{11} \mathrm{~B}$ (relative to some standard) can thus be used to determine ocean $\mathrm{pH}$, assuming that organisms incorporate boron into their structures without isotopic dependence. The boron should be obtained from the tetrahedral structure $30 \%$ of the time if $30 \%$ of oceanic boron is in this form, for instance. Experiments show that this is true or at least very nearly so.

Figure 15 suggests a huge drop in ocean $\mathrm{pH}$, from 8.5 to 7 . This would require about $10 \%$ atmospheric carbon dioxide, but the accuracy of this last prediction is low. The main benefit of this research is in 


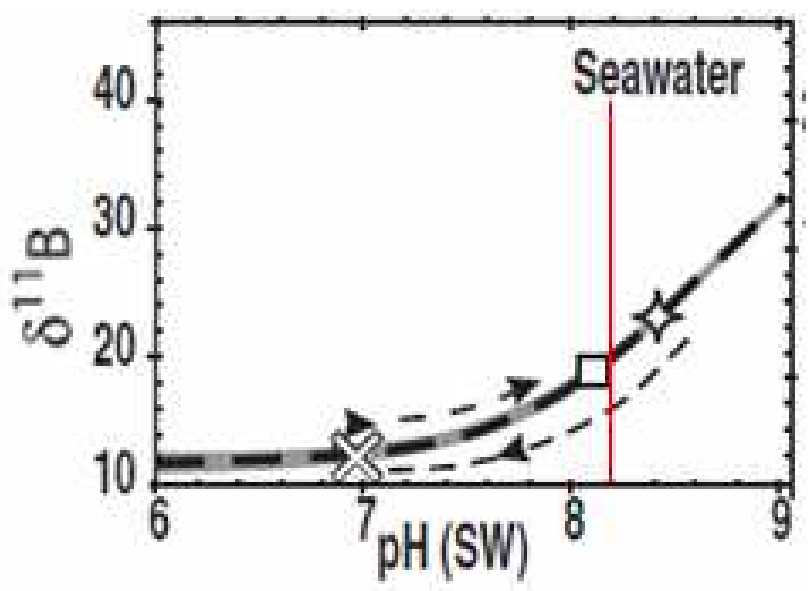

Figure 15: Trajectory followed by ocean $\mathrm{pH}$ during the Sturtian Glaciation. The $\mathrm{pH}$ dropped to 7 and had not fully recovered to its pre-glacial value of 8.5 by the end of the period explored. The modern value for ocean $\mathrm{pH}$ is 8.2 .

showing that a huge drop in ocean $\mathrm{pH}$ probably did occur. Extreme changes in ocean chemistry are therefore compatible with the data.

\section{Banded iron formations}

Evidence has also accumulated in the form of widespread banded iron formations. It is thought that the oceans would contain iron, and when oxygen levels rose, allowing it to oxidise; it would precipitate out as iron oxide. However, if the production of oxygen suddenly decreased, then this would almost stop and only carbonates and silicates would be deposited. These are iron poor.

Iron is thought to have been quite common on surface rocks (and thus in the ocean) because it is the heaviest stable isotope that can be formed inside a sufficiently heavy star while releasing energy by nuclear fusion (so it has the lowest binding energy per nucleon). This iron and other elements heavier than helium (and a little of elements heavier than iron) would usually be released when the star exploded as a corecollapse supernova. Some of it could then be incorporated into the Earth as it was forming.

The iron would not be precipitated out by hydroxides because the oceans were probably acidic in the past. This is due to higher levels of carbon dioxide required to counteract the fainter Sun (it increases in power output by $10 \%$ every billion years). This arises because the helium forming in the Sun from hydrogen accumulates in the core, and a helium nucleus occupies less volume than 4 hydrogen nuclei. This leads to a higher core density and thus pressure. The temperature is forced to rise to maintain hydrostatic equilibrium. This speeds up the fusion reactions, leading to a higher power output from the Sun, and probably a larger Sun as well (it is nearly an ideal gas).

The acidic oceans would have been able to retain (in a dissolved form) iron weathered from surface rocks and from hydrothermal vents. Variations in the level of oxygen would have caused variations in the rate of deposition of iron oxides (which are insoluble), especially near the critical point where the ocean was just about to get saturated with oxygen (or oxygenated). These variations may be seasonal in nature (Figure 16). Banded iron formations are rare since about 2.4 billion years ago, near when oxygenic photosynthesis first became widespread enough to oxidise all oceanic iron. However, they suddenly reappear about 750 million years ago, concurrent with the proposed global glaciation events. The dissolving of oxygen from the atmosphere into the oceans would be almost completely halted by ice cover, preventing the deposition of iron in the oceans (this time predominantly hydrothermal in origin) (Figure 17) [14].

However, there would be a sudden and very large amount of iron being deposited at the end of the glaciation, when the atmosphere suddenly became oxygenated. This would lead to a banded iron formation, as the oxidation of iron in the ocean would be somewhat non-uniform. Some of the banding may be due to seasonal upwelling of deep waters that had not yet been oxygenated (and thus were iron rich), leading to a lot of iron oxide forming and being deposited; but only in some seasons.

BIFs have been observed, but not everywhere due to the unique geologic conditions needed for them to form and be preserved until the present day. Thus, some sceptics maintain that they formed only in inland seas which were ice covered, not in oceans.

Another objection is that a high obliquity of the Earth's axis with respect to its orbital plane could lead to glaciation near the Equator but not near the poles. Thus, the glaciation would not be global in extent. However, the Moon has a stabilising effect on this important parameter of the Earth, currently $23.5^{\circ}$. Even without it, a change to the very high values required by this hypothesis and then to lower values again on timescales of less than 100 million years is considered to be quite unlikely. Also, open oceans near the poles (or anywhere) appear to be ruled out by banded iron formations.

Some of the data could have alternative explanations, but many people now feel that the Snowball Earth hypothesis is best at tying them

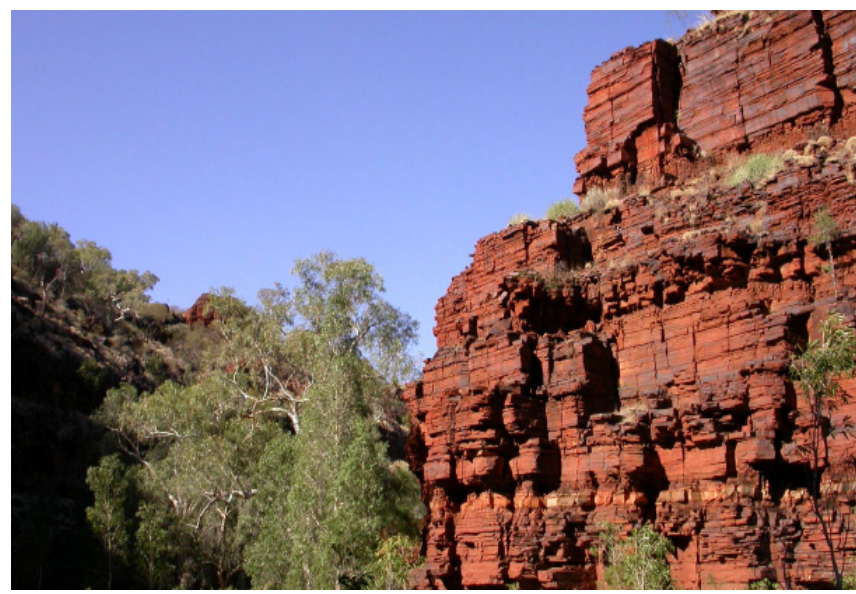

Figure 16: A banded iron formation lay down as a sedimentary rock.

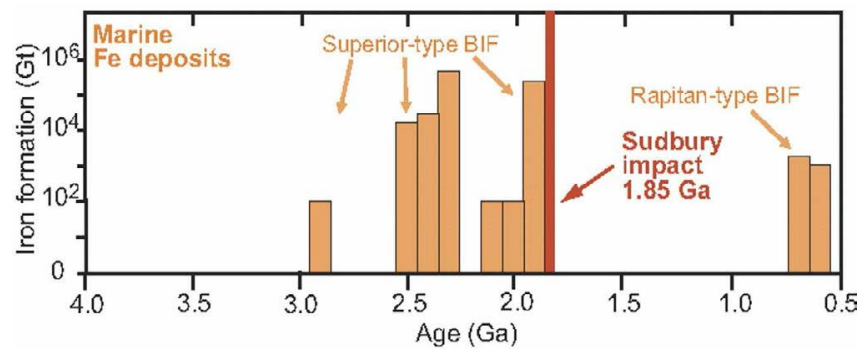

Figure 17: Occurrence of banded-iron formations over 100 million year intervals. The Sudbury impact may have drastically altered the evolution of life, but its effect remains unknown. These formations reappear just (and only) at the time in which glacial deposits were apparently laid down near the Equator. 
all together into a coherent picture of what actually occurred to cause several fairly enigmatic features to appear in the geologic record. The events were very long ago, however, so some caution is needed.

\section{Effect on Living Organisms}

The extreme global glaciations thought to have occurred around 600 million years ago would have had a big impact on the organisms living at the time. It was before the Cambrian explosion in which all of the 11 animal phyla (a broad category) emerged, so only single-celled algae and cyanobacteria had yet evolved.

The critical thing for such simple autotrophic (self-sustaining) organisms is sunlight and liquid water. It is now thought that there would be small regions of open water even during a global glaciation, probably close to the Equator. Evidence has been found for wavecreated ripples in the sedimentary record from this time. Thus, it is reasonable to conclude that at other times the ice could not have been extremely thick (Figure 18) [15]

Some climate models, notably by James F. Kasting at Pennsylvania State University in the USA; suggest that the ice may have been quite thin at the Equator $[16,17]$. This is because of sublimation (ice going directly into water vapour) due to the high levels of sunlight at the surface. Ice would of course flow in from regions further from the Equator, but there are limits to how fast this would occur. This would limit the ice thickness to only a few metres, and possibly not more than about $30 \mathrm{~m}$. Enough sunlight penetrates this much ice to allow cyanobacteria to survive below it [18].

Evidence suggests that completely ice-free regions did temporarily exist, although none have been found that was ice-free throughout an entire Snowball Earth event. Poleward of even $13^{\circ}$, there was too little sunlight penetrating to the bottom of the ice sheet to maintain the depth. This would rise further, rapidly eliminating solar radiation at the bottom. A new type of equilibrium would be set up, with geothermal heat (fairly weak compared to sunlight) holding back the ice sheets from completely freezing the entire water column in the deep oceans. The ice sheets could have been more than $1000 \mathrm{~m}$ thick in these parts, and the prospects for life look bleak. It seems that only a quarter of our planet, maybe much less, was habitable. However, this is still a lot more than nothing, so it is possible for life to have survived in it.

Exploration of the deep oceans has led to the discovery of some of the strangest organisms known to us, including extremophiles that, as their name suggests, can survive extreme conditions. Extremophiles survive at the very limit of known habitable conditions. Hydrothermal

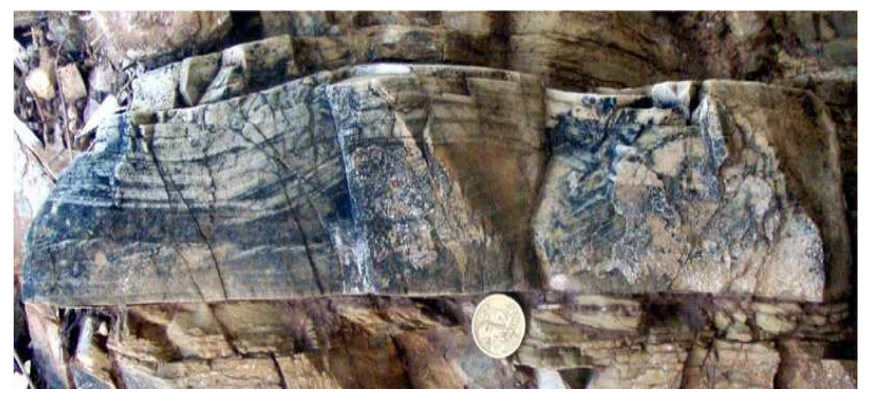

Figure 18: Irregular glacial deposits in Southern Australia were nonetheless affected by waves, creating the (very visible) wavelike undulation in this photograph. At the time of deposition, the oceans here must have had stormgenerated surface waves, implying no ice cover. A coin is provided for scalethere would probably be no coins and no humans without such ice-free regions. vents in the deep sea, often called black smokers, are some of the places where they can live. These are places where water circulates through magma very close to the ocean floor, getting very hot and leaching chemicals (some of which are quite important to life, leading to relatively high biological productivity near these places). The idea is that, because these organisms do not require sunlight to survive, and probably could survive without oxygen derived from oxygenic photosynthesis; they could survive throughout the entire glaciated period.

It is now known that hyperthermophiles, as they are called, can survive at temperatures of up to $120^{\circ} \mathrm{C}$. These are different from most organisms known to have existed both before and after the Snowball Earth events, so a different explanation is required for surface-dwelling photosynthetic organisms. However, this shows that life, of some form, would certainly have been able to survive the global glaciations.

The survival of photosynthetic organisms under kilometres of ice is certainly impossible, because almost no sunlight will get through this much of even the clearest ice. It took major effort even to synthesise glass that clear! However, the ice need not have been very thick at the Equator. The key thing is the reflectivity of tropical sea ice during a Snowball Earth event, and how much sunlight reached the bottom of the ice.

If surface-dwelling life survived a global glaciation, it likely did so in the Equatorial regions. There, sublimation of the ice would occur (this is where it goes from solid to vapour directly). This is balanced by the flow of ice from more poleward regions, but ice flows very slowly. Also, it is possible that repeated cycles of sublimation and ice flowing in would lead to a residue of dust forming on the surface of the ice. This may have led to a little surface melting of the ice and aided in its sublimation. It is entirely possible that the effect of this is to make it take an extremely long while for the ice to advance towards the Equator (some models show a roughly exponential approach). This may have allowed photosynthetic organisms to survive on the Earth's surface while thick ice never quite managed to reach the Equator before the glaciation ended.

Some models suggest, however, that freshly fallen snow due to tiny amounts of sublimation in polar regions would reflect so much sunlight that the ice sheets would be able to advance all the way to the Equator and be several hundred metres thick even there, leading to a so-called 'hard snowball'. This kind of situation would appear to be disastrous at first sight. However, even in this situation, it is quite possible that, without sunlight providing sufficient heat to keep the Equatorial sea ice thin, another heat source could-geothermal heat. This is possible only in tectonically active regions, but there are always some. Also they could conceivably have been in the Equatorial regions, especially if a near-Equatorial supercontinent broke up.

For geothermal heat to reach close to the surface of the oceans, it is necessary to have something like a volcanic island chain (e.g. Hawaii). This kind of situation could lead to the areas just offshore of such an island remaining ice-free or having quite thin ice during a global glaciation. The total area exposed in this way, although tiny compared to the entire ocean, might still have been enough for surface-dwelling life to survive.

Thus, it seems that, whatever model we use to predict sea ice thickness and however the Snowball Earth may have occurred, life would have survived near hydrothermal vents and probably on the surface as well. However, especially in the volcanic island scenario, life may have been in many different and vastly separated 'oases', with no genetic interaction possible and thus very different adaptations to unique conditions. 
Combined with the extreme stress that would have been put on any life that did manage to survive, this may have significantly accelerated the pace of evolutionary change. Under such stress, life, especially of a simple nature, often responds to deliberately seek inaccuracies in copying DNA from one generation to the next. This is more likely to find the 'correct' adaptations than just trying the same genetic structure as before, which is unlikely to be particularly useful as organisms were probably suited to much warmer conditions than those during a global glaciation.

There may have been more than one Snowball Earth event. Combined, these could conceivably have led to the evolution of a wide diversity of life. Then, when the last global glaciation (the Gaskiers) ended about 580 million years ago, some of these organisms went on to become the first land-dwelling animals that ultimately evolved into us. Other organisms remained in the oceans but much more advanced than before.

Even without the global glaciation, the breakup of a supercontinent would open up a huge number of new coastal niches. These would be colonised by organisms, but different adaptations and genes would be required to do this efficiently. However, continents have almost certainly broken up before, so this alone seems insufficient to trigger an evolutionary explosion of the type observed.

The sea level would have changed by as much as 500 metres, mainly due to large land glaciers melting but also because of thermal expansion of the water. This would have led to continental shelves, which contain a wide diversity of organisms; repeatedly being dried and then flooded. When they are dried, the organisms there initially try to survive drier conditions and then die (land organisms did not yet exist). When the area is flooded again, different organisms may conquer it. This may have selected for organisms that were big enough to keep up with the water or to live on land.

In fact, we see a sudden appearance of fairly advanced life forms just after the last global glaciation in what is known as the Cambrian Explosion. This seemed like a big problem to Darwin when he first put forward the theory of evolution by natural selection, because life was not supposed to appear suddenly in a fairly advanced form. We now know that there is a lot more than what gets preserved as fossils (the general shape of the organism and its body plan).

Internal molecular changes were undoubtedly occurring prior to the Cambrian explosion, and once the period of global glaciations ended due to the land no longer being concentrated in the Equatorial regions; life was able to spread rapidly, taking advantage of these new traits where it helped. The combination of organisms living in locations that were previously widely separated through sexual reproduction (which evolved at least 1 billion years ago) would have led to a melting pot where a huge number of different things were tried out. This is just the right kind of situation necessary to initiate an evolutionary explosion of the type observed.

\section{Effect on Living Organisms}

\section{Oxygen}

The rise of large land-based animals seems to have been a very difficult and possibly unlikely accomplishment. Of course, the complexity associated with this is enormous. However, 3 billion years is also a long time, even when compared with the age of the universe! Thus, something special seems to have been required for this to occur.

Animals require oxygen, and this requirement scales with the volume of the animal (roughly), whereas their capacity to acquire oxygen scales with their area if they breathe through their surface. This limits the size, and therefore the complexity; of animals. There is a possible way around this obstacle other than the evolution of advanced lungs (which is not helpful while the animals are still in the ocean but still require a lot of energy to grow and maintain). The very primitive 'lungs' that were already in existence, or were adapted from pre-existing traits; would have worked much better if there was substantially more oxygen in the atmosphere.

At the time of the global glaciations, oxygen levels were nearly at their modern level. This had been the situation for some time. It appears to still have been insufficient for the purposes described. With the Snowball Earth events, it seems there came a pulse of oxygen in their aftermath. The way this would have occurred is fundamentally similar to an algal bloom caused by agricultural runoff. These occur due to increased levels of nutrients like nitrogen and phosphorus, which are the constraints on algae populations and hence oxygen production, at least on geologic timescales. This has led to suggestions of putting iron into the ocean in order to significantly increase carbon dioxide uptake and thereby limit the extent of anthropogenic climate change (assuming the organisms sink into deep waters when they die, preventing oxidation).

Phosphorus is a light element, so while the Earth was molten (just after formation), the phosphorus rose to the surface and floated above the other elements. Thus, it is found mainly on continents and relatively little comes from hydrothermal activity. Higher levels of phosphorus would have been delivered by the erosion of glacial deposits that formed during the global glaciation. These are readily weathered. Such weathering proceeds in normal times as well, but in the aftermath of a global glaciation, the concentration of carbon dioxide would be very high ( $10 \%$ or more).

This would lead to a very high temperature, about $50^{\circ} \mathrm{C}$, just after the glaciation. Such a high temperature would lead to huge quantities of evaporation from oceans (due to the Maxwell-Boltzmann Distribution Law-at higher temperatures, more water molecules have sufficient energy to escape as a gas). Also, warmer air can hold much more water vapour than cooler air (more spaces between air molecules). Water vapour is a greenhouse gas, so this amplifies the warming due to the carbon dioxide (or other factors) even further. Eventually, the water vapour would fall as rain and so the amount of rainfall, and thus of weathering, would be very high.

The higher temperatures would eventually return to more normal conditions as the high weathering rate drew down some of the carbon dioxide. However, this is thought to take a lot of time, with a roughly exponential decrease pattern (as a lower temperature would reduce the rate of weathering). Thus, the phosphorus 'spike', such as it was, would be fairly long-lived.

The phosphorus should leave some trace in the geologic record. Scientist Noah Planavsky of the University of California at Riverside has, along with others, attempted to trace the proportion of iron to phosphorus in what are known as ferruginous (iron-based) sediments [19]. Phosphorus is in competition with silica for adsorption onto these sediments, the iron of which is mostly hydrothermal in origin. Thus, with a good understanding of silica levels, it is possible to determine how much phosphorus was in the oceans at the time the deposits were formed. Silica levels have changed drastically in the Earth's long history. It is thought that this is mostly driven, at least in the last billion years; by the evolution of diatoms that use it in their structure and then sink to the ocean floor, thereby locking it up. Before this occurred (at the 
very most 300 million years ago) silica levels would have been much higher. This would lead to a lower amount of phosphorus adsorbing onto the ferruginous sediments (for an equal actual concentration of phosphorus in the oceans) (Figure 19).

What the scientists found for the past 500 million years was just what was expected-higher phosphorus ratios were in recent times (because the competing silica is now heavily used by organisms) and much lower ratios before the diatoms evolved. A calculation shows that the actual amount of phosphorus in the oceans was little different.

However, 600-800 million years ago, a different pattern emerges. The amount of silica is not thought to have significantly changed between then and the evolution of diatoms. However, the ratio of phosphorus to iron was very much higher. This suggests that phosphorus really was present at a higher actual concentration.

This could fairly easily be explained by the Snowball Earth hypothesis. The glaciers would have caused some erosion and put phosphorus directly into the oceans even in the glaciated state, but this would proceed especially rapidly after deglaciation due to very high (and acidic) rainfall. The erosion caused by the glaciers would be increased due to periodic changes in variables like ice thickness that are Milankovitch-driven.

Variations in orbital parameters of the Earth such as the eccentricity of its orbit and the tilt of the Earth's axis with respect to its orbital plane vary in a periodic manner due to the gravitational effects of other bodies in the solar system. These change the amount of sunlight incident on the surface and so can change the thickness of the ice in a periodic manner. This would lead to more erosion than a relatively steady state where nothing much happened until carbon dioxide levels rose to the point at which the glaciers started melting. It also explains some evidence that has been found of variations in conditions during the glaciated period.

If phosphorus levels really were high, and photosynthetic organisms required it (which is almost certain), then there would have been a huge algal bloom after the Snowball Earth events. Some evidence has been found for this, although most of it is just a rebound to pre-glacial levels. Upon death, some of the algae (after producing oxygen) would sink to deep parts of the ocean and not get oxidised. Thus, the oxygen they produced would remain in the atmosphere, leading to net accumulation of it.

Oxygen was required for large and complex life, especially if it was to colonise the land. How much oxygen there was prior to the global glaciations is uncertain, but probably not more than $15 \%$. After them, the level was more than double that. This would really have helped

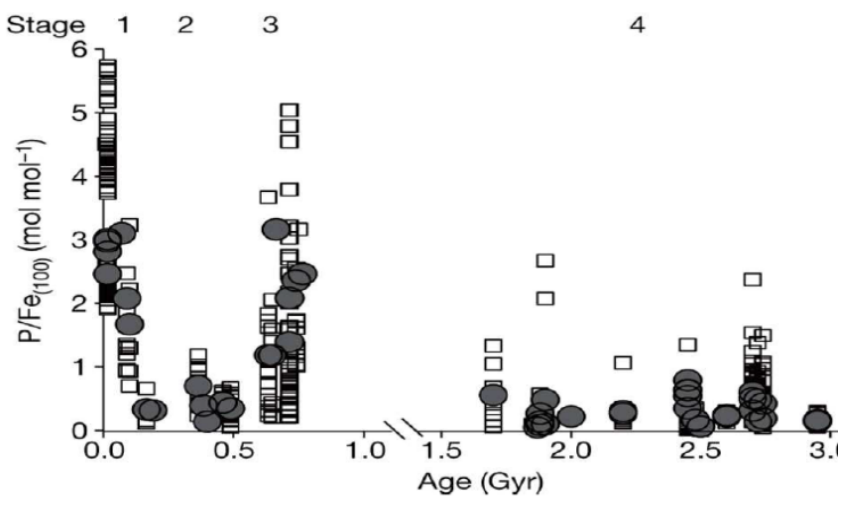

Figure 19: Ratio of phosphorus to iron in ferruginous sediments. larger life forms to not get starved of oxygen. Critical bio-chemicals like collagen, required to form body structures that support the organism against gravity; are not thought possible to have been produced without oxygen levels near $40 \%$, although higher efficiencies in its production could reduce this requirement (Figure 20) [20].

The size, and the option of escaping onto the strange and unfamiliar land; would carry an evolutionary advantage. This comes from escaping predation. This was particularly important after the evolution of eyesight, which had taken place by this time-it was much harder to hide, but size could allow defences like hard shells to be grown (while still leaving enough room for essential functions). A large increase in size could even turn the tables on who was predator and who was prey.

In this way, we see that higher oxygen levels could have allowed the evolution of large animals. These would be capable of climbing onto land and also being more complex than what had gone before. Once this had occurred, oxygen levels would eventually fall, although the duration of the phosphorus and oxygen pulse is unknown.

It is important to recognise that animals were not the only type of life that colonised the land. Microbial mats of photosynthesising cyanobacteria would have managed to colonise the land even earlier It is possible they lived on oceans far from any land and then colonised tidal areas, finally going on to colonise coastal regions and thus land. This process would have been greatly aided by the increase in the area of tidal zones following the breakup of a supercontinent, especially in the warm Equatorial regions.

Evidence from the earliest microbial mats on land would be quite difficult to find, if any has persisted to the present day and is out there somewhere. Thus the exact time at which this occurred is unknown. Adaptations required would include surviving at more extreme temperatures (because these vary on land more than in the ocean), surviving desiccation and resisting gravity (unless they were very small, which is likely). Needless to say, the first of these would have been pre-selected for during a global glaciation. Large changes in sea level might also have forced algae to survive with much less water. Those that managed could colonise the land more easily.

The high temperature and consequent high rainfall may have made the land areas of the Earth much wetter, and therefore easier for initially ocean-based life to colonise them. Little is known of the capacity for such ancient solids to hold on to rainwater. It seems that this is not very high, because the familiar appearance of soil is due to certain bacteria which probably had not yet evolved.

It is possible to envisage a scenario in which the high oxygen and rainfall conditions did not persist for very long, at least on evolutionary timescales. This does not mean that evolution would not have been affected. For instance, the soil could have been made much more favourable and with a higher capacity to retain water if things like algae managed to colonise some parts of the land, helping to break the soil down. Once this had happened, high rainfall might not be necessary any longer, for it is well known that similar organisms are able to survive on biologically altered soils at modern rainfall levels. Once advantageous evolutionary changes had been triggered by temporary environmental changes, the newly evolved traits would persist.

At much later times, soil production would have been greatly accelerated by the evolution of burrowing animals that could churn the soil and accelerate erosion. This would ultimately allow for the evolution of woody plants and flowering plants, which are much more efficient than gymnosperms. Ultimately, this would have led to 


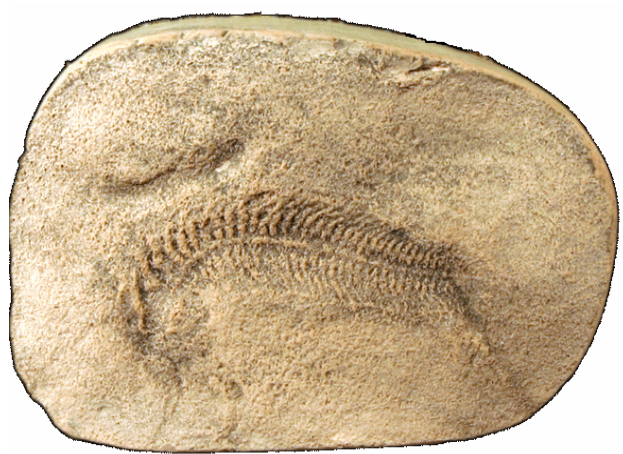

Figure 20: A Pre-Cambrian segmented worm, Spriggina floundersi, dated to $580 \mathrm{Ma}$, just after the last Snowball Earth.

high oxygen levels and the evolution of really large animals such as the dinosaurs. They would probably still be here today were it not for the impact of a large ( 6 mile) object from space, the effects of which are still poorly understood but include the extinction of the dinosaurs and the opening up of new ecological niches for mammals, leading eventually to humans. Evolution was thus quite rapid once the land had been colonised, with arguably much more change since the last global glaciation than in the preceding 2 billion years since the origin of oxygenic photosynthesis on this planet.

Oxygen is one factor among many that allowed something as complicated as the evolution of complex land-based life on this planet. It seems that oxygen levels may have been quite high before the Snowball Earth events took place, but it does not seem that this led to the evolution of complex life-forms. Thus, some of the extreme environmental changes associated with a global glaciation, and the new niches opened up when a supercontinent broke up; seem to be just as important in accelerating the pace of evolutionary change as higher oxygen levels. Drastic evolutionary changes are needed to colonise the land and evolve complexity, and these changes may well need drastic events to select for them. However, we cannot know if they would have occurred without the global glaciation events. Most likely a combination of factors, of which global glaciation was just one; was responsible for the Cambrian Explosion, a remarkable event in evolutionary history without which we would not be here.

\section{The Habitability of Extrasolar Planets}

The Snowball Earth events are quite important in the study of Earthlike planets beyond our own solar system. The key thing for any possible life on such worlds is the size of the habitable zone, defined so an Earthlike planet within it could sustain liquid water oceans on its surface for a specified period of time. Liquid water is thought to be a prerequisite for life. The time period is usually taken to be 1 billion years, sufficient for life to evolve and (in theory) leave traces of it sufficient to be detected on Earth with future technologies, several light years away.

The habitable zone is a useful concept, especially as surface life similar to that on Earth that uses liquid water will be most easily understood and detected (as it changes the composition of the atmosphere). The zone will move out with time, because stars get brighter as they age. Things like the composition of the atmosphere and size of the oceans relative to land, and the general geology of the planet; will be hugely important.

The size of the planet is an important variable, because for the carbonate-silicate cycle to operate, it is necessary to have plate tectonics.
This requires the planet to be sufficiently warm inside. Mars was not geologically active for more than a billion years or so. Ultimately, carbon dioxide was locked up but not released due to the lack of active plate tectonics, cooling the surface down and making it uninhabitable.

The solar wind is a stream of charged particles from the Sun. They are deflected around the Earth, well away from its atmosphere; by its magnetic field. Producing it requires currents flowing in a liquid metallic core (usually iron) and thus a lot of internal heat. The lack of this on Mars allowed carbon dioxide and water to be stripped off by the solar wind, making the planet cold and dry.

For an Earth-size planet, the inner edge of the habitable zone seems to be close to the orbit of Venus (for a Sun-like star). Here, the temperature would be high enough to allow a lot of water vapour to reach the upper levels of the atmosphere. There, it could be broken apart by ultraviolet radiation and the hydrogen could easily escape into space, leading to the water being lost within a specified timescale, usually one billion years. The temperature does not need to be sufficient to actually boil the oceans away, merely to lose them gradually. Insufficient liquid water will cause the carbonate-silicate cycle to stop operating in the usual way because weathering relies on rainfall. This would allow huge amounts of carbon dioxide to build up in the atmosphere and a surface much too hot and dry for living organisms (temperatures around $480^{\circ} \mathrm{C}$ and no liquid water at all). As Venus is geologically active (like the Earth) but suffered from this effect, it seems clear that the habitable zone must start outside its orbit.

The outer edge is poorly constrained, however, because there are no Earth-size planets just beyond it. Without data from our own solar system to constrain this, we need to consider theoretically why a planet would not be habitable if it was too far away. Put simply, the temperature at the surface of any planet will generally be lower the further out it is. Sufficiently far out from the parent star, the oceans would freeze. However, this happened on Earth, and by almost any definition it is habitable! This was because, if the oceans really did freeze over, the carbonate-silicate cycle would keep pumping more carbon dioxide into the atmosphere (assuming a geologically active planet). However, none would be removed by weathering, leading to gradual accumulation.

As already mentioned, greenhouse gases (chiefly carbon dioxide) were responsible for the Earth ultimately breaking out of a global glaciation. Therefore, a reasonable conclusion is that, for a planet to be uninhabitable because it is too far away, a global glaciation must be impossible to break out of as the carbon dioxide would itself freeze out of the atmosphere. Then, the planet would likely remain utterly frozen until its parent star brightened sufficiently to sublimate the carbon dioxide. Habitable conditions would only then begin, at least for surface life of the type we can detect.

Carbon dioxide will freeze at an incredibly low temperature of $-79^{\circ} \mathrm{C}$. However, estimates suggest that this may just have been reached at the poles of a Snowball Earth, but the carbon dioxide ice would probably have sublimated within a fairly short period, assisted by Milankovitch Cycles. After all, once the carbon dioxide gets in the atmosphere, it warms the planet up, and so it can resist by itself the portion of the Milankovitch cycle which would tend to freeze the carbon dioxide again-the planet will be warm enough for this not to happen. It seems clear from the models that the escape would have been very narrow, although the models used may be inaccurate.

Near the edge of the habitable zone, there may be another complication due to the effects on the atmospheric pressure of a high amount of atmospheric carbon dioxide. The greenhouse effect it can 
produce could be limited even further because putting more and more carbon dioxide into the atmosphere of a planet leads to an increase in atmospheric pressure (it is too heavy to escape an Earth-sized planet). For a relatively cool planet, increasing the pressure leads to a higher temperature (there is more carbon dioxide) but only up to a maximum value. The higher pressure also pushes up the temperature at which carbon dioxide condenses out of the atmosphere, and this is quite a significant effect. It is governed by the Clausius-Clapeyron Equation (Figure 21).

Also significant may be the high reflectivity of a planet that contains so much carbon dioxide. It scatters incident sunlight very effectively, and so putting too much into the atmosphere will start to cool the planet down again, causing the curves in Figure 21 to level off. The real value of S/S0 for Mars early in its history is thought to be close to 0.7 . It was somehow capable of sustaining liquid water (there is much evidence from the Mars Exploration Rovers and from satellite photographs of fluvial features). This requires a temperature of close to $273^{\circ} \mathrm{K}$. Thus, the simple models used here are not really what happened. They do illustrate the limits of the greenhouse effect, however.

The concentration of carbon dioxide might also be limited by ocean chemistry that removes it from the atmosphere. This would, for a given rate of volcanic outgassing (depending strongly on planet size), give a maximum value for the concentration of carbon dioxide that could accumulate within the atmosphere. At the outer edge of the habitable zone, this would just be sufficient to keep the oceans of the planet from freezing over (or to deglaciate the planet, if somehow they did freeze over).

Such a calculation might conceivably be useful if it turns out that the planet was only habitable for part of its history (when the amount of incident solar radiation was high enough) rather than since the formation of the planet. This might have a big impact on how we search for life-just after habitable conditions begin, oxygenic photosynthesis would not be widespread but it might well be a few billion years later. Early on, other things like methane could be searched for instead.

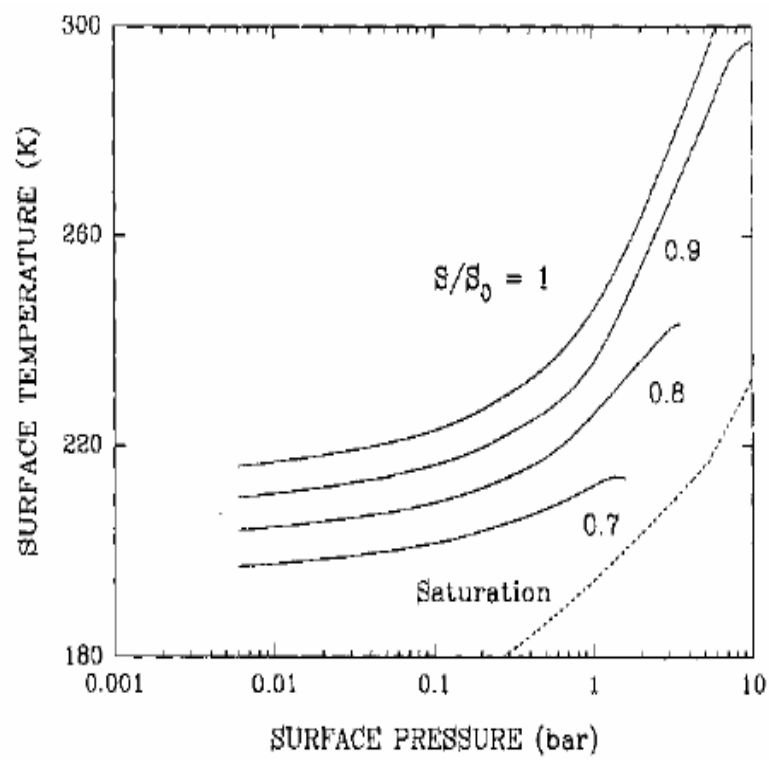

Figure 21: Simulation of Mars under different amounts of solar radiation relative to the present level S0 and different amounts of atmospheric carbon dioxide, assuming a nearly pure $\mathrm{CO}_{2}$ atmosphere. A value of 0.7 will lead to a surface temperature of below $-50^{\circ} \mathrm{C}$. Too high a pressure leads to condensation of the $\mathrm{CO}_{2}$ (dashed line)
Another idea is to find the proportion of area that is land, something that would require better observations than just the mass and radius. If the planet has much more of its surface covered in land, the carbonate-silicate cycle will be more efficient, possibly leading to a lower temperature but still a habitable one. The key thing is that the cycle will also be much more stable, because the probability of all the land being arranged as it was during Snowball Earth is greatly reduced. With above $50 \%$ land cover, the probability drops to 0 , assuming we require all the land to be within $30^{\circ}$ of the Equator. It seems that, although life may develop in the oceans, fewer oceans may be better than more! A waterworld thus seems less stable in terms of its climate, possibly hampering life; although we should not rule it out as we have never seen such a world.

Techniques employed to search for evidence of life would need to be altered based on the ratio of land to ocean. With a lot of land, evidence could be searched for that indicates land-based plants, for instance. Pigments like chlorophyll (which are much more discernible on land than in the ocean) could be searched for, assuming calculations were done of the best colour of the pigment for the plant. This is possible with data on the star and atmosphere, although certain assumptions are required about how the plant will operate. More ocean cover generally leads to more burial of organic sediments to areas where it cannot easily be decomposed using oxygen (the deep ocean), assuming it is produced at all. This would probably lead to higher levels of oxygen (and thus ozone) in the atmosphere, both of which show up on a spectrum.

One exciting possibility is that we discover a completely glaciated Earth-size planet (discovering 100 terrestrial planets will give a good chance of this). Will it remain frozen for billions of years, melting just before its parent star dies; or will it re-emerge in a few million years, replete with complex life forms?

\section{Appendix}

\section{Lead-Lead and Uranium-Lead dating}

The number of U-238 atoms now present, ${ }^{238} \mathrm{~N}$, depends on the original number y by

${ }^{238} \mathrm{~N}=0.5 \mathrm{t} \div 4.5 \mathrm{y}$ (half-life is 4.5 billion years, $\mathrm{t}$ here is measured in billions of years)

Assuming no lead was initially present, the number of Pb-206 atoms, ${ }^{206} \mathrm{n}$, now present is thus given by

$$
\begin{aligned}
& { }^{206} \mathrm{n}=(1-0.5 \mathrm{t} \div 4.5) \mathrm{y} \\
& \text { Thus, }{ }^{206} \mathrm{n}={ }^{238} \mathrm{~N}(2 \mathrm{t} \div 4.5-1)
\end{aligned}
$$

Similarly, ${ }^{207} \mathrm{n}={ }^{235} \mathrm{~N}(2 \mathrm{t} \div 0.71-1)$, where $207 \mathrm{n}$ is the number of $\mathrm{Pb}-207$ atoms of radioactive origin and ${ }^{235} \mathrm{~N}$ is the remaining number of U-235 atoms. The half-life for this decay is 'just' 710 million years.

$$
\text { Dividing, } \frac{{ }^{206} n}{{ }^{207} n}=\frac{{ }^{238} N}{{ }^{235} N}\left\{\frac{2^{t / 4.50}-1}{2^{t / 0.710}-1}\right\}
$$

For a pure lead ore, the ratio $\mathrm{Pb}-204: \mathrm{Pb}-206: \mathrm{Pb}-207$ is about 1 : 17.9: 15.5. For a mixed uranium-lead ore, we expect the proportions of $\mathrm{Pb}-206$ and $\mathrm{Pb}-207$ to be higher. As the original proportion of uranium to lead is not known, we compare how much the $\mathrm{Pb}-206$ has been enriched relative to how much the $\mathrm{Pb}-207$ has been enriched. The stable isotope $\mathrm{Pb}-204$ cannot be formed as a decay product of a naturally occurring radioactive isotope, so it provides a useful reference.

Some of the oldest mixed ores, which formed close to the formation of the Earth itself (or in meteorites); have a ratio of 1: 29.6: 22.6. The 
ratio of $\mathrm{Pb}-206$ and $\mathrm{Pb}-207$ enrichment is thus 11.7: 7.1. This means that the ratio of radioactively derived $\mathrm{Pb}-206$ and $\mathrm{Pb}-207$ must be 11.7: 7.1. These numbers can now be used in the previous equation to deduce that the age of the Earth is 4.56 billion years [21].

Essentially the same procedure is used to date Neoproterozoic rocks. The oldest date from the cap carbonates that form after a global glaciation would be used, this time giving an indication of when the ice age ended.

Sometimes, it is a little simpler than this. Zircons only allow uranium into their structure, so any lead is from radioactive decay. The ratio of ${ }^{206} \mathrm{n}$ and ${ }^{238} \mathrm{n}$ can be used directly (same for ${ }^{207} \mathrm{n}$ and ${ }^{235} \mathrm{n}$ ). The two should agree, but real data are subject to some error. What is obtained is called a concordant age, and is very accurate.

However, the method relies on zircons, which form as crystallisation products inside cooling magma. This requires a volcanic eruption at or very close to the time of interest. Nature does not always oblige, but if it does then this method is more accurate. Many hominid remains between two volcanic layers are dated in this way.

\section{The Clausius-Clapeyron equation}

The Clausius-Clapeyron Equation was devised by Rudolf Clausius and Benoît Paul Émile Clapeyron around 1834. Suppose a closed container has some liquid water in it and some water vapour above it, and nothing else. We assume that the volume of the liquid and the remaining volume do not change much whatever we do to the system, for reasons that will later become clear. The temperature is also assumed to be an independently adjustable parameter, which could be achieved with a good thermal contact between the container and the (temperature-controlled) outside. The pressure is variable and measured carefully, but as we will see the effect of temperature on it is not relevant-it merely alters how long the experiment takes, not its eventual results.

Assuming that a constant proportion of molecules of water are in the surface layer, the rate at which molecules leave the liquid phase and enter the vapour phase depends only on the proportion of molecules that have sufficient energy to do this (energy is required to break the relatively strong intermolecular bonds in the liquid phase).

The proportion of such molecules is given approximately by the Maxwell-Boltzmann Distribution Law, so it goes approximately as some constant times $\mathrm{e}^{-\Delta \mathrm{H}(\mathrm{vap}) / \mathrm{R} T}$. $\mathrm{R}$ is the molar gas constant. The critical parameters are the absolute temperature (measured in degrees Kelvin) and the enthalpy of vaporisation, $\Delta \mathrm{H}_{\text {vap }}$. This is positive, as energy must be put in to break intermolecular bonds (Figure 22) [22].

Now, the equilibrium between the vapour and the liquid phases depends on the rate at which water goes between the two. Temperature is the only factor affecting the vaporisation rate. It is assumed that any molecule in the vapour phase will condense if it should impact the surface of the liquid, however fast it may be going.

We now approximate that only the pressure can affect the rate at which condensation occurs, because for a given temperature the pressure (force per unit area) is dependent only on the rate at which impacts occur with the walls of the container. This is because the speed is fixed by the temperature, so a given temperature leads to a known average speed of molecular motion. Given T, only the frequency of impacts (and molecular mass) can affect the pressure. Assume the condensation rate is $\mathrm{kP}$.
Thus, we see that, for equilibrium between the vapour and liquid phases to exist,

$\operatorname{kmax}$ Peq $=\mathrm{A} \mathrm{e}^{-\Delta \mathrm{H}(\mathrm{vap}) / \mathrm{RT}}(\mathrm{kmax}$ and $\mathrm{A}$ are constants for a particular substance) (Figure 23) [21].

Real air is not pure water vapour. Assume this reduced $\mathrm{k}$ below kmax (value for a pure water vapour atmosphere) and the external atmospheric pressure was equal to Peq as calculated above. Evaporation would then exceed condensation. Water evaporating from a lake or sea would locally raise the concentration of water vapour in the air. This would raise $\mathrm{k}$ towards its maximum value, and eventually condensation and evaporation would be in equilibrium again. Clearly, evaporation can occur with a lower temperature than the boiling point. This is because there is often insufficient time for equilibrium to be established (e.g. winds blow the extra water vapour away).

For boiling to occur, the liquid phase cannot exist in equilibrium with the vapour phase, so we conclude that the external atmospheric pressure needs to be equal to Peq or less for this to occur. This is the vapour pressure condition for the boiling point, Peq = Patm. On a graph of pressure against volume, the boundary of the region in which gas and liquid phases can exist in equilibrium with that where only the

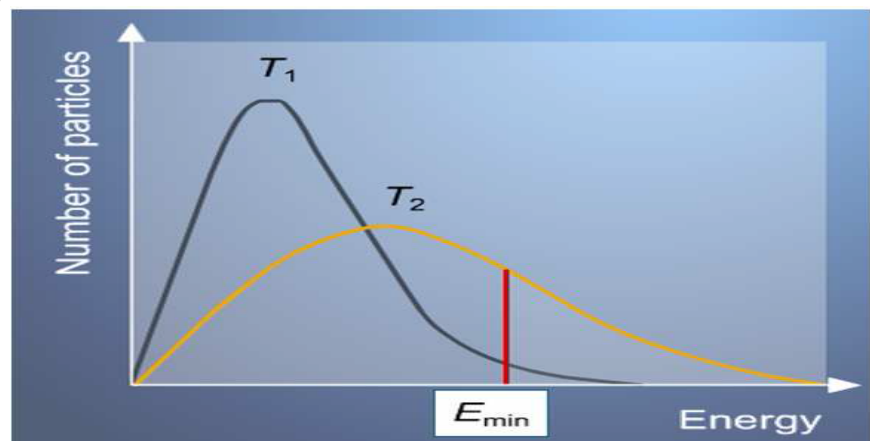

Figure 22: Graph showing the proportion of molecules having various energies, given a fixed temperature. This is shown for two temperatures, with T2 > T1 A higher temperature increases the area under the curves to the right of the red line. This area is the proportion of molecules which have more energy than $\mathrm{E}_{\min }$. The proportion is of course limited to 1 . As long as the red line is well to the right of the peak (most likely) energy value, the exponential approximation used is accurate.

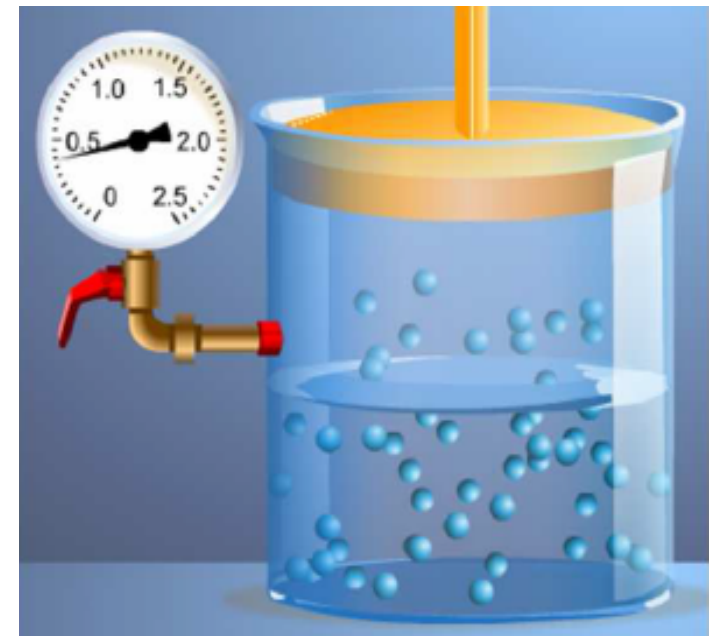

Figure 23: A liquid in equilibrium with its own vapour. The volume here is fixed Peq can be read off as the pressure settles down to this value eventually. 
vapour phase is possible thus follows the equation derived earlier for Peq in terms of $\mathrm{T}$, a rough approximation to the Clausius-Clapeyron Equation which actually works quite well.

One final point is that solid-gas changes occur in a similar way, which is relevant for Mars as liquid $\mathrm{CO}_{2}$ does not exist except at high pressures, so 'condensation' of it would need to involve going directly from a gas to a solid. The enthalpy change here is that of going first into the liquid phase and then into the solid phase. Both enthalpy changes are assumed to be essentially independent of both temperature and pressure.

\section{References}

1. Kasemann SA, Prave AR, Fallick AE, Hawkesworth CJ, Hoffmann KH (2010) Neoproterozoic ice ages, boron isotopes, and ocean acidification: Implications for a snowball Earth. Geology 38: 775-778

2. Harland WB (1964) Critical evidence for a great infra-Cambrian glaciation. Geologische Rundschau 86: 45-61

3. Harland WB, Bidgood DET (1961) Paleomagnetism in some East Greenland sedimentary rocks. Nature 189: 633-634

4. Budyko MI (1969) The effect of solar radiation variations on the climate of the Earth. Tellus 21: 611-619

5. http://www.snowballearth.org/cause.html

6. Harland WB, Bidgood DET (1959) Paleomagnetism in some Norwegian sparagmites and the Late Pre-Cambrian ice age. Nature 184: 1860-1862

7. Hoffman PF, Schrag DP (2000) Snowball Earth. Harvard University.

8. Sellers WD (1969) A global climatic model based on the energy balance of the Earth-atmosphere system. J Applied Meteorology 8: 392-400
9. Kirschvink J (1992) The Proterozoic Biosphere: A Multidisciplinary Study Cambridge University Press 51-52.

10. Hir GL, Ramstein G, Donnadieu Y, Goddéris $Y$ (2008) Scenario for the evolution of atmospheric $\mathrm{pCO}_{2}$ during a snowball Earth. Geology 36: 47-50

11. Bodiselitsch B, Koeberl C, Master S, Reimold WU (2005) Estimating duration and intensity of Neoproterozoic snowball glaciations from Ir anomalies. Science 308: $239-242$

12. Kirschvink, Joseph L, Kopp RE (2005) A Paleoproterozoic origin of Oxygenic Photosynthesis as a trigger for the Makganyene Snowball Earth event. Earth System Processes 2: 11-17.

13. http://www.snowballearth.org/overview.html

14. http://geology.gsapubs.org/content/37/11/1011/F1.small.gif

15. http://news.sciencemag.org/sciencenow/2011/01/snowball-earth-was-dottedwith-p.html?ref=hp

16. Pollard D, Kasting JF (2005) Snowball Earth: a thin-ice solution with flowing glaciers. J Geophys Res 110

17. Kasting JF (1991) $\mathrm{CO}_{2}$ condensation and the climate of early Mars. Icarus 94: 1-13

18. Walker JCG, Hays PB, Kasting JF (1981) A Negative Feedback Mechanism for the Long-Term Stabilization of Earth's Surface Temperature. J Geophys Res 86: $9776-9782$

19. Planavsky NJ, Rouxel OJ, Bekker A, Lalonde SV, Konhauser KO, et al. (2010) The evolution of the marine phosphate reservoir. Nature 467: 1088-1090

20. http://fossils.valdosta.edu/lists/frameset_pages/home_lists_segworm.html

21. International Physics Olympiad (2000) Theoretical Problem 1, part C Radioactivity and age of the Earth. Leicester, UK.

22. http://www.yteach.com/page.php/resources/view_all?id=phase_cooling boiling_s olid_liquid_gas_curve_point_equilibrium_vapour_page 3
Citation: Banik I (2016) Snowball Earth. Astrobiol Outreach 4: 153. doi: 10.4172/2332-2519.1000153
OMICS International: Publication Benefits \& Features Unique features:

- Increased global visibility of articles through worldwide distribution and indexing

- Showcasing recent research output in a timely and updated manner

- Special issues on the current trends of scientific research

Special features:

- 700+ Open Access Journals

$50,000+$ editorial team

Rapid review process

Quality and quick editorial, review and publication processing

Indexing at major indexing services

Sharing Option: Social Networking Enabled

Authors, Reviewers and Editors rewarded with online Scientific Credits

Better discount for your subsequent articles

Submit your manuscript at: http://www.omicsonline.org/submission 